\title{
Capability and Health Functioning in Ethiopian Households
}

\author{
Ramzi Mabsout
}

Accepted: 12 May 2010/Published online: 6 August 2010

(C) The Author(s) 2010. This article is published with open access at Springerlink.com

\begin{abstract}
From a recent Ethiopian representative household survey this paper empirically operationalizes concepts from the capability approach to shed light on the relationship between conversion factors, capability inputs and health functionings. The subjects of the study are women in partnership. The results suggest their health functionings are responsive to specific household bargaining power conversion factors and capability inputs. The paper also tests the extent to which women who take more decisions achieve better health functioning. The model offers evidence that decision-making and health functionings follow a complex pattern as women who took more decisions were not always better off. The conclusion of the paper is that health functioning may be improved by inducing changes to household decision-making patterns.
\end{abstract}

Keywords Capability approach · Decision-making · Ethiopia - Women's empowerment

\section{Introduction}

In the early days of development health policy and family planning assistance was administered on the assumption that availability of health facilities, contraceptive education and information suffice to reduce mortality, fertility and promote socio-economic development. At the same time, it was also becoming clear, more effective results could be obtained if women's empowerment-a demand side factor-was included in the policy mix (Balk 1994; Easterlin and Crimmins 1985; Germain 1975; Malhotra et al. 2002, 21).

Earlier versions were presented at the Income Distribution and the Family conference (Kiel), the NICE seminar (Nijmegen), the Happiness and Capability: Theory, Measurement and Policy workshop (Ravenstein), the Feminist Economics annual meeting (Torino), and the Institute of Social Studies seminar series (The Hague).

R. Mabsout $(\bowtie)$

Radboud University Nijmegen, Nijmegen, The Netherlands

e-mail: ramzimabsout@gmail.com 
Since then, the theoretical and empirical literature on empowerment has expanded and advances on many fronts, including policy ones, have been made. ${ }^{1}$ There now appears to be a consensus that individual empowerment is necessary for improving health outcomes (Diener and Diener 2005, 136,138; Ruger 2010; Santow 1995). Thus, Bloom et al. (2001) suggest socio-demographic characteristics are not sufficient determinants of health outcomes. They argue "direct measure reflecting women's degree of control in their lives" (p. 68) are necessary to explain health outcomes. Malhotra et al. $(2002,9)$ also contend more access to resources does not guarantee greater control over them. In other words, resources are enabling but not empowering. In Ethiopia, Berhane et al. (2001) as well as Kabira et al. (1997), pointed out women's health cannot improve unless women effectively participate in decision-making over resources and access to knowledge.

Household internal dynamics and bargaining power are therefore increasingly acknowledged as instrumental for individual health status. Sahn and Younger (2009), for instance, found that more than half of body mass index (BMI) inequalities in developing countries are explained at the within (not between) household level. These results and arguments give some support to the hypothesis that health status may be to an important extent contingent on empowerment within the household.

In economics of the household, decision-making power emerged as an important variable following the critique of the unitary household model (Chiappori et al. 1993; Quisumbing and Maluccio 2000). In the unitary model, individual and household decisions are taken by a dictator or altruist head. Heterogeneity introduced different, possibly even conflicting, preferences and goals between household members. Still, the possibility of conflicting interests has not ruled out cooperation (Sen 1990; Agarwal 1997). Bargaining models at any rate require decision-making mechanisms (Rubinstein 1991; Sen 2002) that encompass both cooperation and conflict.

There are also several complementary definitions of empowerment in the literature useful to us. For Bali Swain and Wallentin $(2008$, 4), women's empowerment obtains when they challenge "the existing norms and culture of the society they live in". Kabeer (1999) considers empowerment as acquiring the ability of making strategic life choices. Narayan $(2005,4)$ sees empowerment as expansion of freedom of choice and action to shape one's life. While these definitions are not inconsistent, their choice is justified on the grounds that they dovetail with capability as the positive freedom or power individuals have to achieve valuable doings and beings (Alkire and Deneulin 2009, 34). ${ }^{2}$

Concerning the determinants of empowerment, a substantial literature explains it with individual level economic indicators such as access to micro-credit, income and assets. ${ }^{3}$ Thus, compared to all male property rights, joint property ownership of land and houses improves women's decision-making power, their self-confidence and reduces domestic violence (Panda and Agarwal 2005; Datta 2006). Other studies point at higher level determinants including household level factors (e.g., differences in resources between partners) and institutional level factors (e.g., gender norms) moving beyond strictly individual level determinants of empowerment (Doss 2003; Mabsout and Van Staveren 2010).

\footnotetext{
1 See among others, Agarwal (1997), Alkire (2002, 2005b), Alsop et al. (2006), Bali Swain and Wallentin (2008), Beutelspacher et al. (2003), Ibrahim and Alkire (2007), Narayan (2005), Powers and Faden (2006), Samman and Santos (2009), UNDP (1995).

2 For Sen's statements on the capability approach see Sen (1980, 1985, 1993, 1999).

3 See Agarwal (1994), Bali Swain and Wallentin (2008), Cheston and Kuhn (2001), Doss (1994, 2003), Haile (2009), ICRW (International Center for Research on Women) (1997), Kabeer (1999), Pitt et al. (2003), Quisumbing (2003).
} 
Yet, the multidimensionality ${ }^{4}$ of empowerment led to a proliferation of measurement indicators and a subsequent ambiguity over whether it has gone up or down (Kabeer 2001). This multiplicity of indicators is one of the reasons why there remains lingering uncertainties on the relationship between micro-credit and empowerment (Haile 2009). ${ }^{5}$

Indeed, how important empowerment is compared to other factors such as poverty is open to scrutiny (Santow 1995, 147). In addition, there remains uncertainty on the interpretation of a simple linear relationship between empowerment indicators such as decisionmaking in the household and health outcomes. Thus, more empowered women can choose to cooperate and share decisions with their husbands instead of taking them alone. Such a move could also be strategic for women to achieve more favorable health outcomes. But there are only a few, too far in between, and limited in space and time coverage studies for anything firm to established on the relationship between decision-making patterns in the household and none reproductive health indicators (Malhotra et al. 2002; Samman and Santos 2009, 25). Thus, Furr and Nandita (2006) and Hindin (2000) are among the few studies testing the instrumental importance of empowerment for none reproductive health indicators. Much more research is needed to determine whether women who take more decisions in the household are more empowered and, possibly, better off in terms of health outcomes.

Accordingly, the relationship between capability inputs in general and decision-making power in specific with functioning achievement may not be as straightforward as it seems if more capability implies women have to challenge traditional gender norms sparking reduced male support and even punishment. As Mason (2005) points out, there appears to be a positive relationship between violence against women and earnings in countries where women enjoy few rights. In Ethiopia, highly unequal gender norms reflect spousal relationships where women are unable "to play an active role in decisions that affect their position" (Pankhurst 1992, 1). Levine $(1965,79)$ long ago observed how even though Amhara women enjoy property and inheritance rights, they are seen as gossipers and deceivers, are often beaten, even as they sacrifice their lives to please men. The World Health Organization $(1999,25)$ refers to

practices that place specific constraints on women's ability to make decisions... these institutions exist within a broader socio-cultural context in which women's decision making abilities in general remain constrained and subjugated to the political, socio-economic, and cultural dominance of men.

Jejeebhoy (1995, 7-8) concludes similar patterns of gender norms hold in most of Eastern Africa. In Ethiopia, furthermore, Legovini (2006, 142) found that women's awareness of their right is positively related to spousal beating. Thus, where gender norms are unfavorable and human development is low, the implications of decision-making patterns in the household can result in serious harm for women.

Beginning with the ethically grounded concepts of the capability approach, this paper explores the extent to which capability inputs and conversion factors explain objective health functioning indicators. The main objective is to understand to what extent women with more capability and bargaining power are better off in terms of health.

The dataset is the 2005 Ethiopia DHS (Demographic Health Surveys). This survey provides extensive information on household decision-making, resources and health

\footnotetext{
4 See Alkire (2005), Kabeer (2001), Mason (1986, 285), Narayan (2005), Osmani (2007), Williams (2005).

5 The list of empowerment indicators includes labor supply, decision-making in and outside the household, investment in human capital, spending on private goods, feeling autonomous etc.
} 
functionings. Furthermore, because of its multi-ethnic composition and climatic diversity, according to Webb and von Braun (1994, 1-2), Ethiopia is a microcosm for the rest of Africa and the findings may be relevant elsewhere.

The paper is organized as follows. Section 2 covers the main conceptual issues as well as the statistical model. In Sect. 3 data and measurement issues are considered. Section 4 presents and discusses the estimation results. Section 5 concludes.

\section{Conceptual Framework}

The conceptual language of the capability approach is here employed and empirically contextualized. ${ }^{6}$ The objective is to test how in environments of unequal gender norms, conversion factors and capability inputs are instrumental to women's health functionings. Thus, where women are marginalized but important contributors to household and community life (Pankhurst 1992, 7), the paper seeks a better understanding of the pathways from capability to functioning.

This paper's model estimates capability from its inputs-not from extrapolated achieved functionings. ${ }^{7}$ Capability is here operationalized as capability to $x$ where $x$ can be 'to play', 'to be healthy', 'to be happy' or 'to work', among other things. The model, accordingly, aims to operationalize Ruger's $(2010,81)$ definition of health capability as the capability to achieve health functionings.

Figure 1 below highlights the main components of the model, including the various hypotheses to be tested. The model adapts Robeyns's (2005) positioning of the conversion factors before the capability set. Figure 1 also combines Kabeer's (1999) operationalization of capability as emerging from resources (pre-conditions) and empowerment (process) to Robeyns (2004) input capability measurement method. Achieved functionings are positioned on the right hand side as outputs. Capability, thus, not only mediates between the conversion factors and functionings, it also has direct functionings effects.

In Fig. 1, the conversion factors shape the capability set of women with information on three distinct kinds of indicators: individual (age, sex), social (class, ethnicity), and environmental (urban, climate, infrastructure) (Kuklys and Robeyns 2005). These conversion factors are subsequently hierarchically modeled as exogenous indicators and partitioned at individual, household and institutional levels.

The model in Fig. 1 adopts a broad definition of resources involving education and earnings (Kabeer 1999; Narayan 2005). Health, however, is here modeled as an outcome or an achieved functioning. It is in fact a 'fertile functioning' which is necessary to achieve other functionings (Wolffe and De-Shalit 2007, 10).

The determinants of health functioning are the conversion factors and capability inputs. Conversion factors have both direct and indirect (mediated by capability) effects on functionings. Social norms influencing choices are integrated as institutional conversion factor. Equivalently, capability, after controlling for the conversion factors, determines

\footnotetext{
6 Thus, it differs from approaches that model bargaining power in households mostly in terms of resources, including public resources, women income shares, unearned income, assets at marriage, and current assets, among others (Doss 2003; Quisumbing and Maluccio 2000, 18). The latter approaches are subsequently interested in capturing correlations between bargaining power indicators and expenditure patterns across households.

${ }^{7}$ For different approaches to measure capability and functioning with structural equations, see Krishnakumar (2007), Krishnakumar and Ballon (2008), Kuklys (2005), Di Tommaso (2007).
} 


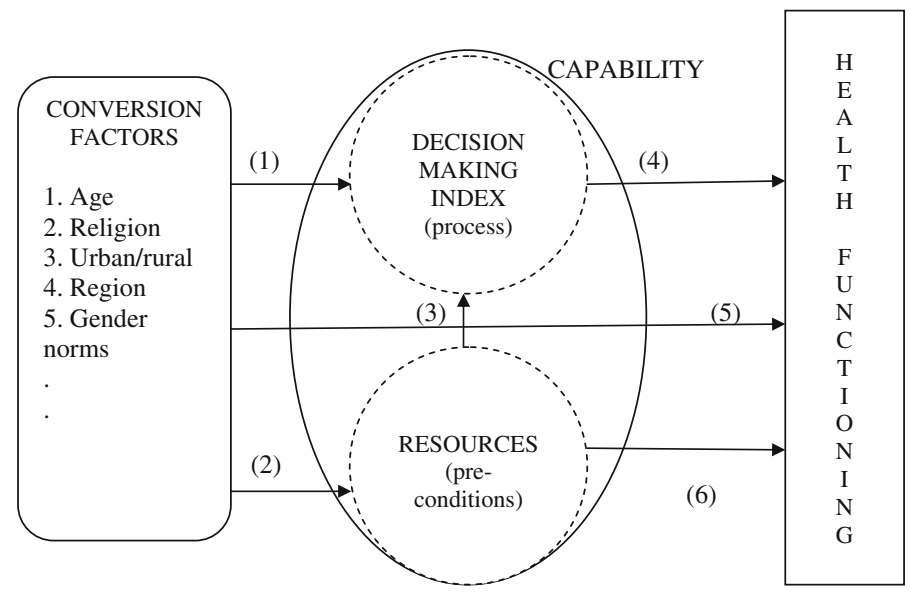

Fig. 1 Conversion factors, capability and functionings

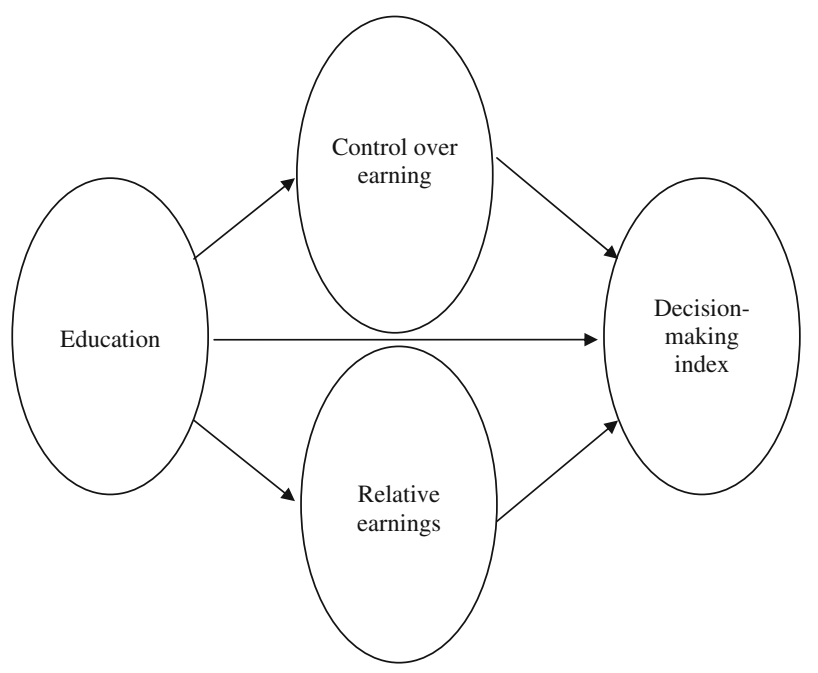

Fig. 2 Relationships between capability inputs in this paper

health functioning. In this model, finally, though indirect (mediated) effects are estimated no interactions (moderating) are computed.

In summary, relationships between conversion factor and capability inputs are marked (1) and (2) in Fig. 1. Relationships between capability inputs are marked (3). Relationships between capability inputs and health functioning, including the indirect effects of the conversion factors on functionings are marked (4) and (6). The direct effects of the conversion factors on functionings are noted (5).

The relationships between the various capability inputs in (3) are modeled in Fig. 2. Education is posited as prior to earnings, control over earnings and the decision-making index. Total earnings could be theorized as causing control over earnings-the more a woman earns the more empowered she will be (Mayoux 1999, 960-962). The relationship between earnings and control over earnings is, however, most likely endogenous-women 
who earn more are more likely to control their earnings but those who control their earnings are also more likely to earn more. To avoid further biasing standard errors, their relationship is not estimated. ${ }^{8}$ Education, earnings and control over earnings are set prior to the decision-making index. In other words, an educated woman who controls her earnings is expected to take more individual and household decisions. A model with total earnings instrumented is also estimated.

This sub-section described how the capability approach components may be empirically mapped and contextualized. The next section further elaborates the statistical properties of the model.

\subsection{A Simultaneous Equations Statistical Method}

Capability is measured from inputs-resources and processes. Here, health functioning is an output to be explained (Robeyns 2005; Strauss and Thomas 1998, 775). In Eq. 1 the general model is expressed.

$$
h=\left[c_{C F}(\eta, r, \rho) ; x\right]
$$

where $h$ is health functioning, $c$ capability, $\eta$ decision-making index, $r$ resources (Education and earnings), $\rho$ control over earning spending, and $x$ the conversion factors calibrating the capability set. The capability function has the subscript $C F$ to indicate it is endogenous and only the conversion factors are truly exogenous.

The four capability inputs education, earnings share, control over earnings, and decision-making are respectively ordered in the system of equations. The decision-making index is therefore not the only capability input. Finally, the four capability inputs and the conversion factors explain health functionings.

Since decision-making in the household is most likely fuzzy, a single indicator can measure it with error. MIMIC (Multiple Indicators Multiple Causes) models can control for error in measurement. They have, accordingly, a measurement and a structural part. In the former, a set of indicators measured with error are aggregated to form an unobservable or latent variable (Mabsout and Van Staveren 2010). However, the observable decisionmaking indicators are manifestations of the latent, error free, variable. Who actually decides in the households (has final say) is an outcome or realization of this latent variable. Statistically speaking, the latent variable is constructed from the correlations between the observed decision-making indicators. ${ }^{9}$ A probit measurement model is employed to estimate the latent variable as in Eq. 2:

$$
y_{i l}^{*}=v_{2 x k}+\Lambda_{l} \eta_{i}+e_{i l}
$$

\footnotetext{
${ }^{8}$ The strategy adopted is to maintain minimum exogenous controls. This choice may, however, lead to another bias, namely, omitted variable bias. However, a pragmatic choice has to be made and in simultaneous system of equations instrumental variables is problematic because it raises interdependence between indicators. The latter renders model estimation difficult. In addition, few structural equations models software at the time of writing incorporate 2SLS computation possibilities. Since 2SLS is manually estimated this is also likely to produce inefficiencies. Still, models with instrumented variable and all the endogenous variables are estimated. For space purposes only the former are discussed here. The results of the model which included all the endogenous variables do not change the substantive findings and can be obtained from the author upon request.

${ }^{9}$ See Kaplan (2000) for an introduction to MIMIC. A specific application to empowerment is provided by Williams (2005) in rural Bangladesh.
} 
Equation 2 encapsulates three $(=k)$ probit equations simultaneously estimated with $v(2 \times k=2 \times 3)$ thresholds and $\Lambda(l=2)$ unstandardized coefficients. $l$ identifies the indicator and $i$ the women.

In Eq. 3, the decision-making index scores, $\eta$, are subsequently regressed on the following 'structural' explanatory variables: conversion factors $x$ (with coefficients $\Gamma$ ), resource capability inputs $r$ (the pre-conditions which include education and earnings with coefficients $\Psi$ ), and the capability inputs control over earnings $\rho$ (with the process with coefficients $\Omega$ ). The conversion factors explain why some individuals have larger, and others smaller, capability sets. In other words, they 'parameterize' the capabilities of individuals. To illustrate, living in urban areas may expand women's access to services, information, and mass media enhancing their capability sets (Abadian 1996, 1802). Resources include education and earnings. Although a probit model estimates the decisionmaking index in Eqs 2, 3 is linear.

$$
\eta_{i}=\alpha+\Gamma x_{i l}+\Psi r_{i}+\Omega \rho_{i}+d_{i}
$$

The output of the model — health functioning - is measured with the body mass index (BMI) and an anemia indicator. These basic health functioning indicators are adequate because no one wants to be in bad health as various other valuable functionings depend on health (Ruger 2010; Wolffe and De-Shalit 2007). As Sahn and Younger $(2009,17)$ also point out, "we feel that BMI should be taken seriously as a measure of well-being in its own right”.

But the choice of functioning indicators is also in large part an ethical one because it expresses a concern for the well-being of Ethiopian women. The other major factor in the choice of functioning indicators is data availability. Nevertheless, it should be observed, the impact of low capability is multidimensional and may not reveal itself as low health functioning achievement.

The third and final equation links health functioning $f$ to capability and conversion factors in $\beta, \lambda, \zeta$, and $\varphi$ :

$$
f_{i}=\delta+\beta x_{i}+\lambda r_{i}+\zeta \rho_{i}+\phi \eta_{i}+\mu_{i}
$$

All descriptive explanatory covariates in the model are listed in Table 5. With categorical variables as dependent variables the statistical package MPLUS uses a WLSMV (Weighted Least Square) ${ }^{10}$ estimator and probit coefficients for categorical dependent variables. ${ }^{11}$ A model with earnings instrumented is also estimated to control for endogeneity as explained below.

In fact, wife income share compared to husband is kept in the functioning regressions notwithstanding potential simultaneity with health which could feed back into wife earning potential. ${ }^{12}$ This choice is justified based on evidence that health and nutrition affect the wage rate of men not women in Ethiopia and elsewhere (Behrman and Deolalikar 1989; Ferro-Luzzi et al. 2001; Pitt et al. 1990; Sahn and Alderman 1988). Furthermore, since the paper uses ratios for wife/husband earnings the feedback from health effect is eliminated as

\footnotetext{
${ }^{10}$ WLSMV, unlike Maximum Likelihood, is not a full information estimator. The limited information approach, however, gives similar results (Muthén 1989, 24, 1993).

11 MPLUS is a statistical software capable of estimating standard linear regressions as well as categorical and multilevel structural equations models. Since a categorical indicator mediates between two variables ( $x \rightarrow u \rightarrow y$, with $u$ categorical) a probit is used for the regression of $u$ on $x(x \rightarrow u)$ and the continuous latent response of $u\left(u^{*}\right)$ for the regression of $y$ on $u(u \rightarrow y)$ (Muthén and Muthén 2008, 405).

12 See Bhargava (1997, 279-80), Dercon and Krishnan (2000), Hando (2009, 151), Strauss and Thomas (1998, 803) among others.
} 
systemic household ill-health is accounted for in the numerator and denominator. ${ }^{13}$ Finally, as Strauss and Thomas $(1998,795)$ conclude, "a key virtue of these health indicators [height, BMI] is the absence of measurement error that is systematically correlated with respondent characteristics (such as income)". In other words, a statistically significant correlation between a health indicator and income is mostly non-spurious.

Another source of endogeneity involves the decision-making index and health functionings. The hypothesis to be tested here is whether women who take more decisions achieve better health. But what about the other effect, namely, that healthier women take more decisions? Although there has not been much research done to explore such feedback effects, the possibility has been ruled out by Hindis $(2000,1526)$ who argues (using the Zimbabwe DHS) that if women's past nutritional status (measured in height) is not correlated with current decision-making patterns in the household, then nutritional status does not affect decision-making power. Because height and decision-making were not correlated, she concluded there is no evidence "poor nutritional status decreases women's bargaining power in the marriage." Since the same relationship was obtained for the 2005 Ethiopia dataset - height is also not correlated with any decision-making indicator yet BMI and anemia are-the feedback effect may be ruled out as well.

In summary, this paper integrates a decision-making index into a larger model to explain health functioning. The decision-making model is a mediating variable alongside other capability inputs including education, relative earnings, and control over earnings. The relationship between the capability inputs, the conversion factors and functionings is tested with the 2005 Ethiopian DHS.

\section{Data and Measurement}

The DHS dataset is rich enough to explore capability approach based empirical models. This section offers an overview of the dataset and discusses measurement challenges. The DHS is a representative secondary data source collected in numerous developing countries including Ethiopia. ${ }^{14}$ The 2005 Ethiopia DHS contains 14,500 households. 540 clusters (145 urban and 395 rural) from the enumeration areas (EA) provided in a previous Population and Housing Survey were selected. Since the male questionnaire was not submitted to all interviewed households this is a sub-sample of the larger data set of Ethiopian women aged 15 to 49 . The weighted couple's sub-sample size has more than 2,000 variables for 3,236 couples. ${ }^{15}$ Pregnant and lactating women are deleted from the sample because their health indicators can vary for reasons unrelated to the available conversion factors and capability indicators (Sahn and Younger 2009, 21). This deletion reduces the sample size to 2,801 cases. All the indicators used in the estimation exercise are listed and the descriptive statistics reported in Table 2. Some of the indicators are transformed to reduce variance (age) and facilitate convergence (Muthén and Muthén

\footnotetext{
13 As ill-health may be systemic to the household it is included in both partners earning potentials.

14 Weight must be applied to make the regional distribution nationally representative.

15 Some husbands it turned out "stay elsewhere" and their number is 10 . Three of them turned out to be in polygamous relationships (a fourth case was coded as missing value for the variable staying elsewhere but was in a polygamous relationship as well).
} 
2008, 382). ${ }^{16}$ For instance, age is simply divided by ten while for education the square root transformation is used. ${ }^{17}$

Regional dummies are also used as controls because the ultimate indicators to be explained are health functionings. The latter depend on, among other things, climate, access to services and infrastructure which regional dummies are likely to reflect more accurately than ethnic dummies (Frohlich et al. 2001).

One of the mediating dependent variables-women's decision-making index-is measured with the three final say questions. Earlier research explored differences in preferences between male and female partners and attempted to untangle the impact of household decision-making on women's welfare. ${ }^{18}$ In Ethiopia, Webb and von Braun $(1994,77)$ observed, female headed households (widows, divorcees, or wives of soldiers) earn less than male headed households (US\$53 versus US\$62 per person) but spend absolutely more on food (US\$18 versus US\$16). Such empirical work highlights for instance women's role in the household-and the ensuing gender division of labor and responsibilities-leading to patterns of spending in which, for given income and wealth brackets, women spend proportionally larger amounts on food and health than men (Doss 2003; Thomas 1990).

The household decision-making indicators are final say type questions. Three possible answers are offered to respondents, namely, someone else has final say, shared final say and alone final say. Decisions for daily needs are excluded because they follow a different pattern. Table 1 shows for instance that about $50 \%$ of Ethiopian women in relationships have final say "alone" for household daily needs due to gender roles in the household. This is confirmed by Legovini $(2006,142)$ who also found $67 \%$ of women in Addis Ababa and Amhara take small consumption decisions on their own. Legovini also reported as few as $16 \%$ take their own decision for big food items and only $10 \%$ for other important items. Table 1 reveals somewhat similar percentages of decisions taken alone with only $12 \%$ for own health, $10 \%$ for large household purchases, and $8 \%$ for who to visit (Table 2).

Questions on gender norms differ from decision-making indicators because they reflect socially held beliefs on the adequacy of behaviors (Legovini 2006, 141-143). Questions on norms are here modeled as institutional conversion factors. These indicators include husband response to questions on husband right (right to: get angry, refuse financial support, use force for unwanted sex, have sex with other women) and husband and wife responses to questions on wife beating justification (beating justified if she goes out without telling him, if she neglects the children, if she argues with him, if she refuses to have sex with him, if she burns the food). The indices for husband right and beating justification are estimated outside the model with principal component analysis. An index which takes the difference in answers by partners for wife beating justification is also computed. To interpret the index, a statistically significant coefficient for difference in wife beating justification implies couples hold different views on wife beating justification. The variable is positive when wife states beating justified but husband states beating not justified and negative when wife states beating not justified and husband states beating justified. A positive coefficient in the regression with

\footnotetext{
16 They argue, "convergence problems may occur when the range of sample variance values greatly exceeds 1-10. This is particularly important with combinations of categorical and continuous outcomes" (Muthén and Muthén 2008, 382).

17 The square root transformation also reduces the impact of very high educational achievers. In this sample very few women have more than 5 years of education.

18 See for example, Cheston and Kuhn (2001, 8-9).
} 
Table 1 Proportions for decision-making indicators

\begin{tabular}{|c|c|c|c|c|c|c|c|c|}
\hline & \multicolumn{2}{|c|}{$\begin{array}{l}\text { Wife final say } \\
\text { health }\end{array}$} & \multicolumn{2}{|c|}{$\begin{array}{l}\text { Wife final say large } \\
\text { household purchases }\end{array}$} & \multicolumn{2}{|c|}{$\begin{array}{l}\text { Wife final say } \\
\text { household daily } \\
\text { needs }\end{array}$} & \multicolumn{2}{|c|}{$\begin{array}{l}\text { Wife final say visits to } \\
\text { family and relatives }\end{array}$} \\
\hline & Frequency & Percent & Frequency & Percent & Frequency & Percent & Frequency & Percent \\
\hline Someone else & 983 & 35 & 1,254 & 45 & 434 & 15 & 541 & 19 \\
\hline Shared & 1,481 & 53 & 1,267 & 45 & 965 & 34 & 2,039 & 73 \\
\hline Alone & 336 & 12 & 280 & 10 & 1,401 & 50 & 220 & 8 \\
\hline Total & 2,800 & 100 & 2,800 & 100 & 2,799 & 100 & 2,800 & 100 \\
\hline
\end{tabular}

Source: Demographic Health Surveys Ethiopia 2005

In italic-bold maximal values

decision-making as the dependent variable thus implies that in relationships where wives say beating norms are justified and husbands not, women score higher on the decision-making index. However, a positive coefficient also implies wives who disagree with the beating norms in relationships with husbands who think beating is justified, score lower on the decision-making index.

At the individual level, other explanatory indicators include wife age (conversion factor), years of formal education and control over earnings. At the household level, the capability inputs wife share of income compared to husband and the conversion factors age difference between partners, household wealth, and whether husband is in a polygamous relationship are also included. Since the difference in years of education between partners resulted in convergence problems, this indicator was excluded. A possible cause is multicolinearity with wife education since only a few households are educated at all. Finally, at the institutional level, urban, religion, and regional dummies are included.

\subsection{Health Functioning Indicators}

The choice of functioning indicators is a challenging task, especially since most of them feedback into capability. In practice therefore it is extremely difficult to identify a pure functioning which does not involve feedback effects. In light of this, objective health functioning indicators were selected from the DHS. The most fitting indicators were the body mass index (BMI) and the anemia indicator. According to the literature reviewed above and further elaborated on below, these variables are important health indicators in the Ethiopian context and offer attractive statistical properties.

Malnutrition is a chronic problem in various regions of Ethiopia as past famine spells haunt the present and the future (Hando 2009; Webb and von Braun 1994). Abate (1993, 152) reports approximately $7 \%$ of all hospital death in Ethiopia were related to malnutrition and anemia. The BMI is a sex and age independent current nutrition indicator equal to weight (in kilograms) divided by the square of height (in meters). The mean BMI in the 2005 Ethiopia DHS is 20.21 - a unit less than the Sub-Saharan Africa mean of 21.2 for the period 1957-1994 (Pelletier and Rahn 1998). The index captures energy levels stored in the body (Dercon and Krishnan 2000) and offers a direct and easy individual statistic reflecting current nutritional status 'net of needs' (Sahn and Younger 2009, 14). The BMI is also negatively correlated with morbidity, illness, poor birth outcomes, and higher mortality rates (Dasgupta 1993, 414-5; Dewan 2008, 8; Fogel 1994; James 1994; Sahn and Younger 2009; Scrimshaw 1996). As a short to medium-term health and nutrition indicator 


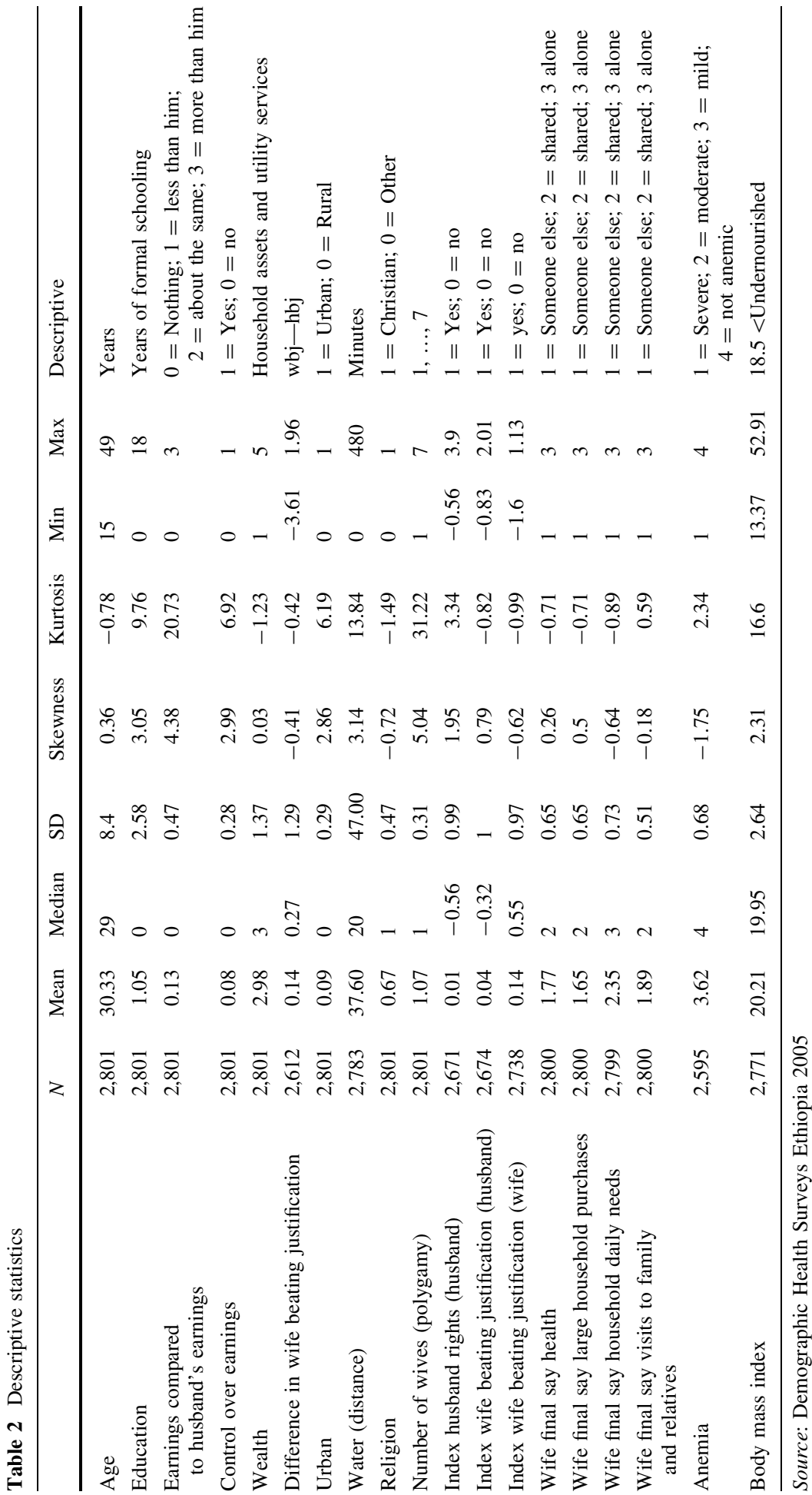


it is less affected by measurement and reporting errors than calories intake and provides "information on intra-household allocation patterns and on the presence of gender bias in the allocation of food and health" (Molini et al. 2010, tbd).

The WHO considers a BMI value under 18.5 as underweight. But to Shetty et al. (1994), this is not necessary and individuals with a BMI under 18.5 may not be chronically energy deficient. Shetty et al. (1994) argue, in fact, a cut off of 17 is more appropriate. Dasgupta contends a BMI range between 15 and 18.5 is an indication that the person is at risk. Furthermore, in population with low body fat stores, additional weight loss leads to loss of lean tissue such as muscles and internal organs (Ferro-Luzzi et al. 2001). A healthy BMI spans the 18.5-25 range. Above 25, the BMI signals overweight. Since few individuals in the DHS sample have a BMI above 25 it will not have a large effect on the estimates. Still, because of the decreasing health returns to higher and higher levels of BMI the logarithm is used.

Additional empirical research shows BMI changes with age even though there is no a priori expected direction of change. However, in both poor developing and developed countries, BMI fluctuates with seasons (Ferro-Luzzi et al. 1994). This fluctuation is especially strong in rural areas of developing countries. Rural farmers may maximize their energy availability for the harvest season only to experience lower BMI in the lean preharvest season. It is reported in some seasons adults can lose up to $10 \%$ of their body weight (Dercon and Krishnan 2000; Dasgupta 1993, 417). According to Ferro-Luzzi et al. (2001), seasonal energy stress in Ethiopia occurs even in normal harvest years and affects more men than women. However, in rural Ethiopia, unlike Gambia, men undertake almost all energy demanding jobs. In addition, James (1994) observes, women with the lowest BMI have the least fall in weight with seasonal shortages. Women (and children) in Ethiopia in fact work at a moderate rate all year long doing low intensity, often postharvest, livestock, and other nonfarm activities (Hando 2009, 59). Ferro-Luzzi et al. also suggest in rural areas of Ethiopia the energy needs of adults are often not met to reduce children's seasonal nutritional fluctuations. Since this DHS survey was conducted between April 27 and August 30 2005, the rural population (about three quarter of the sample), should have been in the post harvest season (the harvest month dare October-January; USDA 2006). ${ }^{19}$ Nevertheless, according to the World Food Programme, 2004 and 2005 were good harvest years that produced surplus and the last draught occurred in 2002/2003 (WFP 2005). Be that as it may, it is difficult to predict in advance the direction and extent to which the seasonal bias has affected the results.

In the 2005 Ethiopia DHS anemia prevalence among women was collected as a categorical variable with four categories: severe, moderate, mild, and not anemic. It is estimated that more than $30 \%$ of Ethiopian population is anemic (Rispin 1998). Anemia is caused by insufficient iron intake and reflected in the amount of oxygen in the blood. According to the University of Maryland Medical Center (2008),

even mild anemia can reduce oxygen transport in the blood, causing fatigue and a diminished physical capacity. Moderate to severe iron-deficiency anemia is known to reduce endurance. Some studies indicate that even iron deficiency without anemia can produce a subtle but still lower capacity for exercise.

Over the long term, anemia leads to secondary organ dysfunction, damage, and heart failure. Anemia increases the chances for poor pregnancy outcomes and affects cognitive

${ }^{19}$ In southern Ethiopia, the period May-August is the worst in terms of food shortage (Ferro-Luzzi et al. 2001, 11). 
and motor of children and adolescents as well as mortality rates among the elderly (Farah et al. 2005; University of Maryland Medical Center 2008).

The nutrition data shows the following patterns. Out of 2,771 cases, $24 \%$ are considered at risk with a BMI under 18.5. In Kenya and Ghana these rate are lower at 6.4 and $16.4 \%$, respectively (Garcia and Kennedy 1994). For anemia, about $28 \%$ of the sample suffer from mild to severe anemia.

\subsection{Descriptive Analysis}

In Table 3 the regional distribution and shortfalls from the means of BMI and anemia are listed. The table shows for BMI most regions are slightly under the means whereas a few regions (e.g., Addis Ababa) are significantly above the mean. The standard deviation of BMI mean differences is eight times larger than the ones for anemia (1.17 and 0.15). Dercon and Krishnan (2000, 694) estimate for rural areas over the period 1994/1995 the north $(\mathrm{N})$ has the highest mean BMI. The current data suggest a different mapping where the north reveals a negative deviation from the mean. The DHS statistics, being more recent and representative of the entire Ethiopian population, indicate the centre (C) of the country enjoys the largest positive mean BMI deviations. For anemia, Addis Ababa has the largest positive deviation from the mean while Afar, Somali and Gambela the largest negative deviation.

As expected, (results not reported) urban women achieve better health functionings than rural women and the differences are statistically significant. This should not come as a surprise when $70 \%$ of all Ethiopians live more than 3 days' walk from a health centre (Abate 1993, 153; see also Berhane et al. 2001, 1526). Table 4 also shows that the poorest fifth have statistically significant lower mean BMI and anemia scores compared to the richest fifth.

Table 4 compares health and decision making scores for groups with some educational attainments against no education. According to Furuta and Salway (2006) education

Table 3 Regional health functioning indicators

\begin{tabular}{llllr}
\hline & $\begin{array}{l}\text { Body mass } \\
\text { index }\end{array}$ & Anemia & $\begin{array}{l}\text { Mean difference } \\
\text { body mass index }\end{array}$ & $\begin{array}{l}\text { Mean difference } \\
\text { anemia }\end{array}$ \\
\hline Tigray (N) & 18.86 & 3.60 & -0.82 & 0.00 \\
Afar (N) & 19.53 & 3.38 & -0.15 & -0.22 \\
Amhara (N) & 19.52 & 3.57 & -0.16 & -0.03 \\
Oromya (S) & 19.82 & 3.59 & 0.14 & -0.01 \\
Somali (SE) & 19.54 & 3.37 & -0.14 & -0.23 \\
Ben-Gmuz (NW) & 18.73 & 3.50 & -0.95 & -0.10 \\
SNNP (S) & 19.63 & 3.68 & -0.05 & 0.08 \\
Gambela (W) & 19.14 & 3.41 & -0.54 & -0.19 \\
Harari (CE) & 20.24 & 3.65 & 0.56 & 0.05 \\
Addis Ababa (C) & 22.95 & 3.85 & 3.27 & 0.25 \\
Dire Dawa (CE) & 20.38 & 3.58 & 0.70 & -0.02 \\
Overall mean & 19.68 & 3.60 & 0.17 & -0.04 \\
\hline
\end{tabular}

$C$ center, $E$ east, $W$ west, $N$ north, $S$ south

Source: Demographic Health Surveys Ethiopia 2005 
Table 4 Education and health functioning

Source: Demographic Health Surveys Ethiopia 2005

\begin{tabular}{lcr}
\hline & \multicolumn{2}{c}{ Education } \\
\cline { 2 - 3 } & \multicolumn{1}{c}{ Yes } & \multicolumn{1}{c}{ No } \\
\hline Anemia & 3.72 & 3.59 \\
Body mass index & 20.99 & 19.98 \\
Wife final say health & 1.84 & 1.75 \\
Wife final say large household purchases & 1.78 & 1.62 \\
Wife final say household daily needs & 2.46 & 2.31 \\
Wife final say visits to family and relatives & 1.91 & 1.88 \\
\hline
\end{tabular}

Table 5 Decision-making indicators and health functioning

\begin{tabular}{|c|c|c|c|c|c|c|c|c|}
\hline & \multicolumn{4}{|c|}{ Body mass index } & \multicolumn{4}{|l|}{ Anemia } \\
\hline & Health & $\begin{array}{l}\text { Large household } \\
\text { purchases }\end{array}$ & $\begin{array}{l}\text { Daily } \\
\text { needs }\end{array}$ & Visits & Health & $\begin{array}{l}\text { Large household } \\
\text { purchases }\end{array}$ & $\begin{array}{l}\text { Daily } \\
\text { needs }\end{array}$ & Visits \\
\hline $\begin{array}{l}\text { Someone } \\
\text { else }\end{array}$ & 19.89 & 19.87 & 19.76 & 19.84 & 3.59 & 3.61 & 3.57 & 3.58 \\
\hline Shared & 20.34 & 20.41 & 20.12 & 20.28 & 3.66 & 3.64 & 3.61 & 3.64 \\
\hline Alone & 20.53 & 20.72 & 20.4 & 20.38 & 3.51 & 3.57 & 3.64 & 3.52 \\
\hline
\end{tabular}

Source: Demographic Health Surveys Ethiopia 2005

Maximal values highlighted in italic bold

improves women's well-being because it is linked to more use of health care as well as spousal discussion of family planning leading to an increased likelihood of receiving antenatal and delivery care. The effect of education, they argue, operates in part via increased discussion between couples so women are able to influence decision making without challenging gender or age hierarchies.

Women with no education have lower BMIs and anemia scores. The differences are statistically significant at the 5\% level. Furthermore, except for decisions concerning family visits, educated women take significantly more decisions in all dimensions, including daily household needs.

Table 5 explores whether women who take more decisions have better health and nutrition. In southern rural Ethiopia the majority of married women $(89.3 \%)$ require permission of husband to visit a heath facility (Berhane et al. 2001, 1534). Although means are above the 18.5 threshold, the results in Table 6 show women who answered someone else takes decisions have the lowest BMI. Thus, in the group who took the least decisions one will find the largest proportion of women with a BMI under 18.5. Most of these women are therefore in the borderline region and should still be considered at risk (Molini et al. 2010). Furthermore, the differences between someone else and the sharing and alone categories are statistically significant. For anemia, however, women who someone else takes health, large household purchases and visits decisions achieve better anemia scores than women who take these decisions alone. For anemia scores, in fact, the healthiest women are more likely to be in the sharing decisions group. Furthermore, for anemia, the differences are statistically significant between shared/alone and someone else/shared nut not someone else/alone. These preliminary results suggest that anemia and BMI interact differently with decision-making in the household. In other words, both depend on 
Table 6 Husband rights reported by husband and health functioning

\begin{tabular}{llllll}
\hline & \multicolumn{2}{l}{ Body mass index } & & \multicolumn{2}{l}{ Anemia } \\
\cline { 2 - 3 } \cline { 5 - 6 } & Yes & No & & Yes & No \\
\hline Husband right to: get angry & 20.15 & 20.24 & & 3.61 & 3.63 \\
Husband right to: refuse financial support & 19.97 & 20.24 & & 3.62 & 3.62 \\
Husband right to: use force for unwanted sex & 20.14 & 20.21 & & 3.54 & 3.63 \\
Husband right to: have sex with other women & 20.21 & 20.21 & & 3.72 & 3.62 \\
\hline
\end{tabular}

Source: Demographic Health Surveys Ethiopia 2005

decision-making patterns in the household. And while BMI achievements appear to be more effectively attained by decisions taken alone, for anemia the best scores are most effectively attained by those who share decisions. The multivariate regressions will confirm whether this correlation is spurious and if the hypothesis can be defended.

Husbands in southern rural Ethiopia may not encourage women to use health care centers and often refuse money to cover the expenses (Berhane et al. 2001, 1531). It is possible to explore the relationship between husband attitudes and wife health. Is there in other words a negative correlation between husband's attitude and wife health? As Table 6 reveals, on one hand, statistically significant differences in means obtain for BMI scores between husbands who answer yes and no to right to refuse financial support while on the other, statistically significant differences in means obtain for anemia with husband answer yes or no for right to force sex and have sex with other women. This negative relationship could be mediated by the existence of a sexually transmitted disease (SDT). While simple linear correlations reveal a positive correlation between husband has right to force sex on wife and SDT, there is no correlation between SDT and anemia. Such bivariate relationships may furthermore be signaling an unmediated relationship between husband's belief and wife health since women engaged to men who think husbands have the right to withdraw financial support have lower BMI scores. Women in such households are presumably in a vulnerable position of dependence. When husbands are in control of income they actualize their threats and withdraw support, undermining women's health.

Since polygamy in Ethiopia is not restricted to Muslims (Levine 1965; Pankhurst 1992, 119-20), has negative physical and psychological effects on women (Kabira et al. 1997, 31), and undermines women's bargaining power, at least among coffee growers (Lim et al. 2007), it is worth exploring its effect on health. Although women not in polygamous relationships have higher BMIs scores the difference is not statistically different (results not reported here). However, in a statistically significant way, women in polygamous relationships take fewer decisions in health, large household purchases, and visits.

Finally, fasting for both Muslims and Christians can affect BMI and anemia. Fasting for Christians in Ethiopia is considered important and expected about 165 days a year (Abate 1993, 134-135; Levine 1965). Fasting Christians avoid the consumption of food from animals. For Muslims fasting occurs in the month of Ramadan. The interviews were conducted between April 27 and August 30 2005, a period outside the yearly fasting calendars. However, while Christians have higher mean anemia scores there is almost no difference between mean BMI scores (results not reported here). 


\section{Estimation}

\subsection{The Measurement Model}

Tables 8 and 9 report, respectively, standardized results for the body mass index and anemia regressions. ${ }^{20}$ The upper panels cover the measurement model for the decisionmaking index and the lower ones the structural equations. The standardized and unstandardized probit coefficients are reported for the measurement model. All the index coefficients are positive and statistically significant which means they are positively correlated. Note that while the health decision-making indicator is fixed to one, standardization reveals its actual weight. The standardized coefficients can be interpreted as follows: for a standard deviation rise in the decision-making index, the latent variable for the indicator for final say on health rises by 0.62 standard deviations.

The index coefficients can also be interpreted in probability terms. Table 7 reports the actual and two standard deviations above decision-making index means probability proportions. As expected, above the mean, the probability of the higher categories rises while that of lower categories falls.

Furthermore, the marginal probability effects of the factor at the mean can be computed for each category and each indicator using the following three equations for large

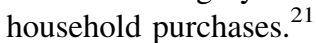

$$
\begin{gathered}
\frac{\partial \operatorname{Prob}[\mathrm{SOMEONE}-\mathrm{ELSE}=1]}{\partial \bar{\eta}}=-\phi\left(\theta_{1}+\Lambda \bar{\eta}\right) \Lambda=-35.2 \% \\
\frac{\partial \operatorname{Prob}[\operatorname{SHARED}=2]}{\partial \bar{\eta}}=\phi\left(-\left(\theta_{1}+\Lambda \bar{\eta}\right)\right) \Lambda-\phi\left(\theta_{2}-\left(\theta_{1}+\Lambda \bar{\eta}\right)\right) \Lambda=22.1 \% \\
\frac{\partial \operatorname{Prob}[\mathrm{ALONE}=3]}{\partial \bar{\eta}}=\phi\left(\left(\theta_{2}-\left(\theta_{1}+\Lambda \bar{\eta}\right)\right) \Lambda=13.1 \%\right.
\end{gathered}
$$

where $\phi$ is the normal distribution function, $\theta_{1}$ and $\theta_{2}$ the estimated thresholds, $\bar{\eta}$ the factor mean, and $\Lambda$ the factor coefficient for the indicator. Note that these probabilities sum to zero. The marginal effects can be interpreted as follows: Eq. 5 suggests the probability of someone else other than the wife taking the decision for large household purchases falls by $35.2 \%$ for a small positive change in the factor score at the mean.

\footnotetext{
20 The proportion of variance explained is of little interest in this model. It is for this reason that testing model fit with $\chi^{2}$ is not meaningful. Overall model testing via $\chi^{2}$ for goodness of fit is not prioritized because there is no interest in explaining the correlations between all the variables. Model fitness is usually tested by minimizing $Q=(s-\sigma)^{\prime} W^{-1}(s-\sigma)$. The sample variance-covariance matrix is $s$ and the model estimated variance and covariance matrix $\sigma$. The difference between data and model covariance/correlation is weighted by $W^{-1}$. Different weight matrices can be specified for $W$ depending, among other things, on sample size, multivariate normality, and whether data are continuous or not. The fit of the model is assessed using the optimal chi-square test $T=n \hat{Q}$ (more details can be found in Kaplan 2000; Muthén 1993). It should also be noted here that the decision-making index is identified simultaneously with the model explanatory covariates. Capability, functionings and conversion factors are measured, and their relationships estimated, together. Testing the decision-making measurement index in isolation is likely to give poor diagnostics, unless its nomological network is included (Bentler 2006, 34-35, 39).

21 These probabilities are derived from the cumulative the probability function. To see this, note that $\operatorname{Prob}[\mathrm{SOMEONE}-\mathrm{ELSE}=1]=\operatorname{Prob}\left[y^{*}<\theta\right]=\operatorname{Prob}[v+\Lambda \eta+e<0]=\operatorname{Prob}[e<-(v+\Lambda \eta)]$, where $\theta$ is the first threshold. The last term is equivalent to $\Phi(-(v+\Lambda \eta))$ and is the area under the normal curve up to the value $-(v+\Lambda \eta)$. By taking the marginal derivative with respect to the factor scores $\eta$ we obtain the normal probability density function (PDF).
} 
Table 7 Actual and estimated probabilities in the measurement model

\begin{tabular}{|c|c|c|c|c|c|c|}
\hline & \multicolumn{2}{|l|}{ Health } & \multicolumn{2}{|c|}{ Large household purchases } & \multicolumn{2}{|l|}{ Visits } \\
\hline & $\begin{array}{l}\text { Actual } \\
(\%)\end{array}$ & $\begin{array}{l}\text { Estimated at } \\
\text { mean }+2 \mathrm{SD}(\%)\end{array}$ & $\begin{array}{l}\text { Actual } \\
(\%)\end{array}$ & $\begin{array}{l}\text { Estimated at } \\
\text { mean }+2 \mathrm{SD}(\%)\end{array}$ & $\begin{array}{l}\text { Actual } \\
(\%)\end{array}$ & $\begin{array}{l}\text { Estimated at } \\
\text { mean }+2 \mathrm{SD}(\%)\end{array}$ \\
\hline Someone else & 35 & 5 & 45 & 11 & 19 & 2 \\
\hline Shared & 53 & 42 & 45 & 46 & 73 & 53 \\
\hline Alone & 12 & 52 & 10 & 43 & 8 & 45 \\
\hline Total & 100 & 100 & 100 & 100 & 100 & 100 \\
\hline
\end{tabular}

For estimating the probabilities see Muthén $(2004,4)$. Results computed for the measurement model only. These probabilities were not obtained from the coefficients in Tables 8 and 9

Source: Demographic Health Surveys Ethiopia 2005

\subsection{The Capability Regressions}

In the lower panel of Tables 8 and 9 the structural regressions are reported. This panel is interpreted once because it is very similar for BMI and anemia. Endogenous indicators are excluded because they bias estimates (see footnote 8 ). ${ }^{22}$ Education, for instance, may delay the age of marriage and reduce the age gap. More educated women are also less likely to engage a man in a polygamous relationship etc. For similar reasons, some of these endogenous indicators are also excluded from the earnings regressions. ${ }^{23}$

The lower panel has five sub-columns, each of which lists coefficients and levels of statistical significance for indicators at the individual, household and institutional levels respectively. The second column from the left is the education linear regression on the conversion factors-hypothesis (2). At the individual level, the standardized coefficient for age is negative $(-0.12)$ and statistically significant. Thus, for a standard deviation rise in the tenth of a year units, (the square root of) schooling years decrease by -0.12 standard deviations. At the institutional level, urban (0.39) and Christian (0.06) are also statistically significant. Thus, non-Christian and rural women are among the least educated. Regional dummy coefficients were relative to the region Oromay. Only one dummy had a positive statistically significant coefficient-the capital, Addis Ababa. The rest are either negative (Afar, Amhara, Somali, and Ben-Gmuz) or statistically insignificant. The dummy patterns of signs and their significance levels are analyzed in a separate section below.

The third column from the left is the relative earnings ordered probit regression. Since it is very similar to the control over earnings regression only this one is interpreted. Also note, the first capability input-education-is added as a covariate in this regression. At the institutional level, urban (0.16) is statistically significant. Thus, the earnings of urban women relative to their husbands are larger than those of rural women. Education-the first capability input to be integrated as an explanatory indicator-is also positive (0.08) and statistically significant. Accordingly, more educated women earn relatively more than less educated women. In a qualitative research exercise representative of the diversity of farming system in Ethiopia, women from most villages (Aze Debo'a, Debre Birhan,

\footnotetext{
${ }^{22}$ From the education regression the following indicators are excluded age gap, polygamy, the norms index for husband rights (husband), the index wife beating justification (wife), difference in wife beating justification index, and wealth.

${ }^{23}$ The model was also estimated with all covariates included. Results do not affect the conclusions and can be made available upon request.
} 
Table 8 Conversion factors, capability inputs and BMI health functioning

\begin{tabular}{|c|c|c|c|c|c|}
\hline & \multicolumn{2}{|c|}{$\begin{array}{l}\text { Standardized } \\
\text { coefficients }\end{array}$} & \multicolumn{3}{|c|}{$\begin{array}{l}\text { Unstandardized } \\
\text { coefficients }\end{array}$} \\
\hline \multicolumn{6}{|l|}{ Decision-making index } \\
\hline \multicolumn{6}{|l|}{ Ordered probit } \\
\hline Wife final say health ${ }^{\mathrm{a}}$ & 0.62 & & 1 & & \\
\hline Wife final say large household purchases & 0.58 & & $0.91 * * *$ & & \\
\hline Wife final say visits to family and relatives & 0.67 & & $1.17 * * *$ & & \\
\hline Standardized coefficients & Education & $\begin{array}{l}\text { Earnings } \\
\text { ordered } \\
\text { probit }\end{array}$ & $\begin{array}{l}\text { Control over } \\
\text { earnings } \\
\text { binary probit }\end{array}$ & $\begin{array}{l}\text { Decision- } \\
\text { making } \\
\text { index }\end{array}$ & BMI \\
\hline \multicolumn{6}{|l|}{ Individual level } \\
\hline Age & $-0.12 * * *$ & 0.07 & 0.06 & $0.08 * *$ & 0.03 \\
\hline \multicolumn{6}{|l|}{ Household level } \\
\hline Age difference & & 0.02 & 0.03 & 0.06 & -0.015 \\
\hline Poorer & & -0.02 & -0.04 & -0.03 & 0.019 \\
\hline Middle & & -0.02 & -0.07 & 0.03 & 0.02 \\
\hline Richer & & -0.07 & -0.10 & 0.07 & 0.017 \\
\hline Richest & & 0.09 & 0.04 & -0.02 & 0.03 \\
\hline Difference in wife beating justification & & & & $0.16^{* * *}$ & 0.021 \\
\hline Polygamy & & -0.04 & -0.05 & $-0.09 * *$ & -0.019 \\
\hline \multicolumn{6}{|l|}{ Institutional level } \\
\hline Urban & $0.39 * * *$ & $0.16^{* * * *}$ & $0.19 * * *$ & $0.09 *$ & $0.18 * * *$ \\
\hline Christian & $0.06 * *$ & 0.02 & 0.04 & 0.06 & -0.02 \\
\hline Index husband rights (husband) & & & & -0.05 & 0.02 \\
\hline Index wife beating justification (wife) & & & & $-0.27 * * *$ & 0.01 \\
\hline Tigray & -0.01 & 0.05 & 0.02 & $-0.13 * * *$ & $-0.09 * * *$ \\
\hline Afar & $-0.02 *$ & $-0.05^{* *}$ & $-0.09 * * *$ & $0.06 * * *$ & -0.02 \\
\hline Amhara & $-0.11 * * *$ & $-0.16^{* *}$ & $-0.13^{*}$ & 0.05 & $-0.07 *$ \\
\hline Somali & $-0.06 * *$ & 0.00 & -0.02 & $-0.18 * * *$ & -0.01 \\
\hline Ben-Gmuz & $-0.02 * *$ & -0.01 & -0.02 & -0.02 & $-0.04 * * *$ \\
\hline SNNP & 0.02 & $0.09 *$ & $0.11 *$ & $-0.18 * * *$ & $-0.06 *$ \\
\hline Gambela & 0.00 & 0.02 & 0.02 & $-0.01 *$ & $-0.02 * * *$ \\
\hline Harari & -0.01 & $0.03^{* * *}$ & $0.03 * * *$ & $0.02 * * *$ & $-0.01 * * *$ \\
\hline Addis Ababa & $0.06 * * *$ & 0.01 & 0.02 & $0.05^{*}$ & $0.03 *$ \\
\hline Dire Dawa & -0.01 & $0.03 * * *$ & $0.03 * * *$ & 0.01 & -0.01 \\
\hline \multicolumn{6}{|l|}{ Capability inputs } \\
\hline Education & & $0.08 * *$ & $0.09 * *$ & 0.002 & $0.10 * * *$ \\
\hline Wife earning compared to husband & & & & $0.11 * *$ & 0.02 \\
\hline Control over earnings & & & & $0.10 *$ & 0.03 \\
\hline Decision-making index & & & & & $0.09 * *$ \\
\hline$R^{2}$ & 0.22 & 0.17 & 0.18 & 0.24 & 0.12 \\
\hline
\end{tabular}

Source: Demographic Health Surveys Ethiopia 2005

$N=2,365$ (unweighted). Dummy is Oromiya. Standardised coefficients unless otherwise specified

${ }^{\text {a }}$ Coefficient fixed to one to identify metric

b Statistical significance of unstandardized coefficients at *** $1 \%$ marked; ** 5\%; *10\% 
Do'oma, Gara Godo, Geblen, Harresaw, Imdibir, Korodegaga, Shumsheha, Sirba, Turufe, and Yetmen) reported in fact education as important and necessary for helping them with organizing, accounting and managing household, farm and off-farm activities (Bevan and Pankhurst 1994).

The fifth column is the decision-making index linear regression. For the decisionmaking regression then, age (0.08) is statistically significant. For a standard deviation rise in the tenth of a year, the decision-making index increases by 0.08 standard deviations. This corroborates Berhane et al. finding $(2001,1534)$ that older women (in rural southern Ethiopia) are more independent in taking health and selling crops decisions. In a different report using Nigerian data, it was observed "age undoubtedly confers influence over decision-making ... [as] a respondent ages, she moves up the household hierarchy" (ICRW 1997, 8). Das Gupta (1996) studied the relationship between women's status and age across the world and argues it is context dependent: in some societies younger women have higher, while in others lower, status. In Ethiopia, nevertheless, older women appear to take more decisions in the household. This pattern has also been observed in Northern India, Pakistan and China (Das Gupta 1996).

At the household level, the conversion factors difference in wife beating justification (0.16) and polygamy (-0.09) are statistically significant. In supporting the interpretation of the polarization index, Williams $(2005,20)$ found in rural Bangladesh women that conform to modesty norms take more decisions compared to women who do not. Nevertheless, as noted earlier, this index must be interpreted with the absolute response women provided for beating justification (as an indicator of gender norms measured at the individual level). Here, there is also no evidence that women in poorer Ethiopian households take less decision as reported elsewhere (Dercon 1999, 25-7).

At the institutional level, the conversion factors urban (0.09) and the gender norms index for wife beating justification reported by wife $(-0.27)$ are statistically significant. Thus, women who challenge the gendered institution of wife beating take more decisions, but when their husbands supports wife beating, the positive effect of women's rejection of the social norm is limited by the negative effect of the fact that she challenges her husband's support for the group norm. ${ }^{24}$

Compared to Oromay, women in Gambela, Tigray, Somali, and SSNP achieve lower scores on the decision-making index. As for the capability inputs relative earning (0.11) and control over earnings $(0.10)$ are both positive and statistically significant. Thus, women who earn more relative to their husbands and who control their earnings take more decisions in the household. Education, however, was not statistically significant. This may be unexpected because a recent survey lists various results which establish a correlation between education and empowerment indicators (Samman and Santos 2009, 20). But the CAS and ORC Macro (2006, 239) Ethiopia report observes an increase in decision-making obtains only beyond secondary schooling. Since most educated women have at most primary education, the decision-making index is expectably statistically insignificant. Bali Swain and Wallentin (2008, 21-22), in fact, found a similar pattern of signs and statistical significance for relative earnings and education in Indian households. In Nigeria, ICRW (International Center for

\footnotetext{
24 Mason $(1987,739-40,2005,91)$ considers women's empowerment in the domestic sphere a function of social and cultural systems (shared norms, values and beliefs) not individual traits and preferences. She contends, for example, the shared belief that men have more rights than women to determine family size affects women's fertility more than individual traits. Mason concludes that most of the variation in women's empowerment is a function of inter-community variation in terms of community values and norms about female-male relations. Thus, country and community level effects predict empowerment more than socioeconomic and demographic traits.
} 
Table 9 Conversion factors, capability inputs and anemia health functioning

\begin{tabular}{|c|c|c|c|c|c|}
\hline & \multicolumn{2}{|c|}{$\begin{array}{l}\text { Standardized } \\
\text { coefficients }\end{array}$} & \multicolumn{3}{|l|}{$\begin{array}{l}\text { Unstandardized } \\
\text { coefficients }^{\mathrm{b}}\end{array}$} \\
\hline \multicolumn{6}{|l|}{ Decision-making index } \\
\hline \multicolumn{6}{|l|}{ Ordered probit } \\
\hline Wife final say health ${ }^{\mathrm{a}}$ & 0.62 & & 1 & & \\
\hline Wife final say large household purchases & 0.58 & & $0.90 * * *$ & & \\
\hline Wife final say visits to family and relatives & 0.68 & & $1.18 * * *$ & & \\
\hline Standardized coefficients & Education & $\begin{array}{l}\text { Earnings } \\
\text { Ordered } \\
\text { probit }\end{array}$ & $\begin{array}{l}\text { Control over } \\
\text { earnings } \\
\text { binary probit }\end{array}$ & $\begin{array}{l}\text { Decision- } \\
\text { making } \\
\text { index }\end{array}$ & $\begin{array}{l}\text { Anemia } \\
\text { Ordered } \\
\text { probit }\end{array}$ \\
\hline \multicolumn{6}{|l|}{ Individual level } \\
\hline Age & $-0.12 * * *$ & 0.07 & 0.06 & $0.08 * *$ & -0.03 \\
\hline \multicolumn{6}{|l|}{ Household level } \\
\hline Age difference & & 0.02 & 0.03 & 0.06 & $0.07 *$ \\
\hline Poorer & & -0.02 & -0.04 & -0.03 & 0.05 \\
\hline Middle & & -0.02 & -0.07 & 0.03 & 0.06 \\
\hline Richer & & -0.07 & -0.10 & 0.07 & 0.07 \\
\hline Richest & & 0.09 & 0.04 & -0.02 & $0.16^{* * *}$ \\
\hline Difference in wife beating justification & & & & $0.16^{* * *}$ & 0.05 \\
\hline Polygamy & & -0.04 & -0.05 & $-0.09 * *$ & 0.01 \\
\hline \multicolumn{6}{|l|}{ Institutional level } \\
\hline Urban & $0.39 * * *$ & $0.16^{* * *}$ & $0.19 *$ & $0.09 *$ & 0.07 \\
\hline Christian & $0.06 * *$ & 0.02 & 0.04 & 0.06 & -0.01 \\
\hline Index husband rights (husband) & & & & -0.05 & 0.02 \\
\hline Index wife beating justification (wife) & & & & $-0.27 * * *$ & $-0.10 *$ \\
\hline Tigray & -0.01 & 0.05 & 0.02 & $-0.13 * * *$ & 0.02 \\
\hline Afar & $-0.02 *$ & $-0.05^{* *}$ & $-0.09 * * *$ & $0.06 * * *$ & -0.03 \\
\hline Amhara & $-0.11 * * *$ & $-0.16^{* *}$ & $-0.13 *$ & 0.06 & 0.03 \\
\hline Somali & $-0.06^{* *}$ & 0.00 & -0.02 & $-0.18 * * *$ & $-0.07 * *$ \\
\hline Ben-Gmuz & $-0.02 * *$ & -0.01 & -0.02 & -0.02 & $-0.02 *$ \\
\hline SNNP & 0.02 & $0.09 *$ & $0.11 *$ & $-0.18 * * *$ & $0.12 * *$ \\
\hline Gambela & 0.00 & 0.02 & 0.02 & $-0.01 *$ & $-0.01 *$ \\
\hline Harari & -0.01 & $0.03^{* * *}$ & $0.03 * * *$ & $0.02 * * *$ & 0.00 \\
\hline Addis Ababa & $0.06 * * *$ & 0.01 & 0.02 & $0.05^{*}$ & 0.04 \\
\hline Dire Dawa & -0.01 & $0.03 * * *$ & $0.03 * * *$ & 0.01 & 0.00 \\
\hline \multicolumn{6}{|l|}{ Capability inputs } \\
\hline Education & & $0.08 * *$ & $0.09 * *$ & 0.003 & 0.02 \\
\hline Wife earning compared to husband & & & & $0.11 * *$ & -0.04 \\
\hline Control over earnings & & & & $0.10 *$ & -0.06 \\
\hline Decision-making index & & & & & -0.06 \\
\hline$R^{2}$ & 0.22 & 0.17 & 0.18 & 0.24 & 0.07 \\
\hline
\end{tabular}

Source: Demographic Health Surveys Ethiopia 2005

$N=2,365$ (unweighted) Dummy is Oromiya. Standardised coefficients unless otherwise specified

${ }^{\text {a }}$ Coefficient fixed to one to identify metric

b Statistical significance of unstandardized coefficients at *** $1 \%$ marked; ** 5\%; *10\% 
Research on Women) (1997) noted, on one hand, a negative relationship between decisionmaking and secondary school attendance and, on the other, a positive one between contribution to household expenditure and decision-making.

\subsection{BMI Regression}

The BMI regression tests hypotheses (4), (5) and (6) in Fig. 1. In the last column of Table 8 the results are reported. Ferro-Luzzi et al. (2001) explain BMI seasonal changes in southern Ethiopia with age, sex, education, per capita land area, value of life stock, household dependency ratio (old and young to working age), and location of residence. Here slightly more than a tenth of the variance in BMI is accounted for by the covariates. Numerous factors which cannot be accounted for here can affect BMI and anemia, including individual activity levels. In addition, according to Liere et al. (1994), the determinants of body weights fluctuation in Benin are related to sanitation and health-not socio-economic status. Although other studies report a positive relationship between household consumption and individual BMI in developing countries (Sahn and Younger 2009,18 ), here this hypothesis is not tested because the DHS has only information on wife relative earnings. ${ }^{25}$ Nevertheless, two capability inputs, education (0.10) and decisionmaking (0.09), are positive and statistically significant. Thus, the decision-making index and education have an independent positive statistically significant relationship with heath functioning.

As Ferro-Luzzi et al. (2001) observed, education protects against seasonal (not chronic) malnutrition in Ethiopia. There is also evidence more educated women have taller daughters because they distribute resources differently in the household (Doss 2003, 51). The importance of education for health gets further support from the anthropological literature cited above which found in various Ethiopian villages shared belief in the benefits of education by, and for, women (Bevan and Pankhurst 1994). In addition, for various Asian countries, Ghuman et al. (2004) using factor analysis show women's answer to empowerment questions has a real impact on their health. Support for this thesis, however, has not been found everywhere since Furr and Nandita (2006) point out decisionmaking autonomy in Nepal is unrelated to BMI. ${ }^{26}$

Since at the household level no indicator is statistically significant, there is also preliminary support to Ferro-Luzzi et al. (2001) who found adult seasonal BMI uncorrelated with wealth in southern Ethiopia.

At the institutional level, urban (0.18) is statistically significant. Urban women therefore have higher BMI than rural women. It is, finally, interesting to observe the pattern of negative regional dummies which maps Webb and von Braun (1994), 21-23) famine belts from the north-east to south of the country. Webb and von Braun (1994) suggested three mutually reinforcing causes for the vulnerability of these regions-population pressure, agro-ecological resource base and climatic regime.

\footnotetext{
25 Attention should be given then to the wealth index which includes access to water as one of its indicators.

${ }^{26}$ However, it should be noted, Furr and Nandita (2006) censored BMI at the critical value of 18.5. In the next sub-section their hypothesis is considered. Their measure of decision making autonomy includes who has final say on own health care, large household purchases, everyday household purchases, making family visits, and what food to cook.
} 


\subsection{Anemia Regression}

The anemia regression (Table 9) has a lower r-square. However, some household level indicators are now statistically significant including age difference (0.07) and the richest group (0.16). The age difference index suggests bargaining power is important since smaller age gaps improve anemia scores. A lower age gap in the bargaining literature entails more bargaining power for the women because relatively older women are able to secure better nutrition, less physical work and better access to health services. With more bargaining power women can improve the household exchange rate for chores and food distribution. This is sensible if, as reported in the anthropological literature, Ethiopian women in rural areas work for very long hours, often eat after everyone has eaten and the least nutritious pieces (Bevan and Pankhurst 1994; Pankhurst 1992). Furthermore, if only the richest can afford regular meat consumption and meat helps the body absorb iron, the relationship between wealth and anemia correlation is plausible (Rispin 1998).

At the institutional level, women's response to beating justification $(-0.1)$ is statistically significant. Women therefore who agree beating is justified are more likely to be anemic. This offers further support to our hypothesis that the health anemia functioning indicator is sensitive to household bargaining power indicators.

None of the capability inputs is statistically significant. Yet, as observed in Table 5, the highest anemia scores are achieved by women who share decisions not those who take them alone. Figure 3 displays the kind of relationship hypothesized between empowerment and decision-making. It supports the idea that empowerment is relational (Samman and Santos 2009) as well as Sen's $(2001,56)$ observation that "we live in a world in which being completely independent of the help and goodwill of others may be particularly difficult to achieve, and sometimes may not be the most important to achieve."

In the following sub-section, the linear relationship between BMI and the decisionmaking capability input is further explored. Nevertheless, the differences between anemia health functioning - which may not be easily diagnosed-and BMI health functioning requires additional research. Here it is only possible to speculate. One implication is that more individual decision-making power can raise the quantity of food ingested by women but not quality. Thus, women who display more cooperative decision-making patterns with husbands may have access to more nutritious food, including meat, which raise iron levels in the body, enhancing the amount of oxygen carried in the blood and reducing anemia.

Thus, more decision-making in the household is conceptually and empirically distinguished from more empowerment. For instance, it is reported by Cheston and Kuhn (2001,

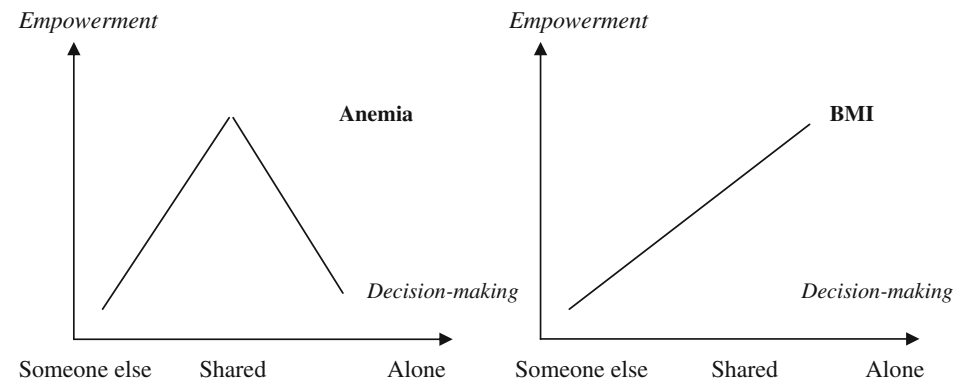

Fig. 3 Hypothesized relationship between decision-making and empowerment for different health functioning 
38) that although micro-credit can improve women's decision-making with respect to the purchase of household assets in Ghana, men have not changed their beliefs about gender roles.

In summary, this model is useful as a first step to learn more on (1) which regions in Ethiopia have the largest shortfalls in health functionings; (2) which conversion factors at the individual, household and institutional levels have the strongest relationships with health functioning; (3) and which of the capability inputs are related to health functioning. In the next subsection robustness and refinements are added to further learn about the interrelationships between the different inputs of the model.

\subsection{Robustness Checks}

Sensitivity checks to test the robustness of the results are undertaken to explore the reliability of the findings. First, if "it is difficult to disentangle the cause and effect relationships between women's decision making power and women's income" (Doss 1996, 2), the endogeneity of wife (relative to husband) earnings may be problematic. The standard econometric endogeneity test-the Wu-Hausman test-is not included in most structural equations programmes. Furthermore, as Foster and McLanahan $(1996,258)$ argue, combining logistic with instrumental variable estimation is problematic "when the second stage" involves non-linear function (e.g., decision-making, anemia).

A good instrument should correlate with the "endogenous" variable and related to the dependent variable only through the mediator. It should also be uncorrelated with the residuals. However, the detection of simultaneity through the Wu-Hausman test is contingent on the choice (and availability) of good instruments (Morgan and Winship 2006). Unless such instruments are found, endogeneity cannot be established unambiguously. Baltagi (1998, 272-3) recommends using all exogenous indicators in the system of equation, insuring the number of exogenous variable is superior to the endogenous variables to identify the system, and at least one exogenous variable not included in the original regression. Thus, in predicting the adjusted earnings variable all the covariates with the instruments should be included (Foster and McLanahan 1996). The choice of exogenous instrumental variable is based on Kambhampati (2009, 91) who employs regional mean earnings to instrument wife earnings (when decision-making power is the dependent variable). ${ }^{27}$

The instrumented variable model with bootstrap standard errors is estimated. Bootstrap are necessary to correct standard errors obtained from two stage least squares (Antonakis 2009; Foster and McLanahan 1996). Two versions are considered-one with the noninstrumented earnings indicator as a dependent variable and the other with the instrumented variable as dependent variable. Thus, in the former model, two earnings indicators are integrated, namely, the unadjusted (as a dependent variable) and the instrumented as an independent variable in the decision-making and functioning regressions. This model, however, did not converge. The alternative model employed the instrumented earnings across the board and converged. A weakness in the latter model is that the regression in which earnings is the dependent instrumented variable is perfectly predicted. With earnings instrumented, the positive correlation between earnings and decision-making no longer obtains. However, control over earnings remains positively correlated with

\footnotetext{
27 Furthermore, although Kambhampati (2009) employs wife age and education as instruments this is not possible here because they have a direct effect independent of relative earnings on decision-making power (Morgan and Winship 2006).
} 
decision-making. Functionings wise, instrumented earnings remain uncorrelated with BMI and anemia.

As a second robustness check, the continuous (BMI) and ordered categorical dependent (anemia) health functioning indicators are replaced with binary ill-being indicators. A BMI cut-off for the BMI at 18.5 is set (Dasgupta 1993; Furr and Nandita 2006). Accordingly, women with BMI scores under 18.5 are coded one (others zero). Similarly, for anemia, women scoring below or equal to three (the mild anemia level) are coded one (not anemic zero). The regression coefficients now reflect the probability of being undernourished and/ or anemic.

For space purposes only the BMI results are reported (Table 10). The sign of the coefficients now reverse because dependent variables reflect the probability of ill-being. For the 18.5 cut-off regression, urban, education, the decision-making index and some regional dummies are no longer statistically significant. The significant predictors are now age (0.09), relative earnings (-0.11) and control over earnings (-0.13). A similar negative

Table 10 Continuous and binary BMI regressions

\begin{tabular}{lccc}
\hline & BMI & $\begin{array}{l}\text { BMI 18.5 cut-off } \\
\text { binary probit }\end{array}$ & $\begin{array}{c}\text { BMI 20 cut-off } \\
\text { binary probit }\end{array}$ \\
\hline Age & 0.03 & $0.09^{* *}$ & 0.03 \\
Age difference & -0.01 & 0.04 & 0.03 \\
Poorer & 0.02 & 0.00 & -0.02 \\
Middle & 0.02 & -0.05 & -0.03 \\
Richer & 0.02 & -0.08 & -0.04 \\
Richest & 0.03 & -0.10 & -0.02 \\
Difference in wife beating justification & 0.02 & -0.02 & 0.05 \\
Polygamy & -0.02 & 0.02 & 0.04 \\
Urban & $0.18^{* * *}$ & -0.07 & $-0.22^{* * *}$ \\
Christian & -0.02 & -0.04 & 0.04 \\
Index husband rights (husband) & 0.02 & -0.04 & -0.01 \\
Index wife beating justification (wife) & 0.01 & -0.06 & -0.03 \\
Tigray & $-0.09^{* * *}$ & $0.07 * *$ & $0.11^{* * *}$ \\
Afar & -0.02 & 0.00 & 0.01 \\
Amhara & $-0.07^{*}$ & 0.01 & 0.04 \\
Somali & -0.01 & 0.04 & 0.01 \\
Ben-Gmuz & $-0.04 * * *$ & $0.03 * *$ & $0.05^{* * *}$ \\
SNNP & $-0.06^{*}$ & $0.09 *$ & 0.03 \\
Gambela & $-0.02^{* * *}$ & $0.02^{* * *}$ & $0.01^{*}$ \\
Harari & $-0.01^{* * *}$ & $0.02^{* *}$ & $0.02^{* *}$ \\
Addis Ababa & $0.03^{*}$ & 0.03 & 0.03 \\
Dire Dawa & -0.01 & $0.02^{* *}$ & $0.02^{*}$ \\
Education & $0.10^{* * *}$ & -0.03 & $-0.06^{*}$ \\
Wife earning compared to husband & 0.02 & $-0.11^{*}$ & 0.03 \\
Control over earnings & 0.03 & $-0.13^{*}$ & -0.01 \\
Decision-making index & $0.09 * *$ & -0.02 & 0.09 \\
$R^{2}$ & 0.12 & 0.09 & \\
\hline & & & \\
\hline
\end{tabular}

Source: Demographic Health Surveys Ethiopia 2005 
relationship with age and BMI was observed in Ethiopia by Ferro-Luzzi et al. (2001), 26-28) who conclude "the [negative] association was particularly strong among women, suggesting that older women may constitute a nutritionally vulnerable group". At such low levels of BMI, older household members could be sacrificing for younger members. In Ethiopia there is some evidence this may occur quite often (ibid., ix). Alternatively, older women are less able to bargain and secure their nutritional needs (Hando 2009). However, the latter hypothesis is less likely because the model in Tables 8 and 9 reveal that older women take more decisions signaling that they could be in charge-and purposefully in control of-food distribution within the household.

The results also indicate wives who earn more than their husbands and who control their earnings have lower probabilities of experiencing a BMI under 18.5. In other words, the more women earn compared to their husbands and the more control they have over these earnings, the more they can insure their individual adequate nutrition.

The decision-making index, however, fails to explain why some women have a BMI below, while others above, 18.5. It is possible, still, that the decision-making index can explain a different BMI cut-off. Indeed, a third regression codes BMI scores under 20 as one. Now, the urban dummy $(-0.22)$, education $(-0.06)$ and the decision-making index $(-0.09)$ are negative and statistically significant. In other words, a high score on the decision-making index, living in an urban zone and education reduce the probability of BMI falling below 20. Below this threshold, women's decision-making index is not related to the distribution of nutrition and work efforts to her favor. A possible explanation which has received some support in the literature is that women with low BMI and high scores on the household decision-making index are diverting resources to feed other members, possibly children (Ferro-Luzzi et al. 2001, 49; Hando 2009, 59; Sahn and Younger 2009, 27; Sen 1990). Only after other members of the household have been fed, women use their bargaining power to improve own nutrient intake and work effort distributions. $^{28}$

As for the binary anemia regression, the results are almost unchanged. The decisionmaking index approaches statistically significant with a positive coefficient in support of Fig. 3. Age difference $(-0.08)$, the richest household dummy $(-0.12)$ and the wife beating justification index $(0.1)$ are statistically significant. Thus, women who agree with husband beating justification have higher probability of being anemic. The relationship between the wealthiest group and both health indicators supports the intuition that access to a rich diet and basic amenities-such as water and latrines - are goods and services only the richest households benefit from. As late as 2006, in fact, $60 \%$ of the Ethiopian population did not have access to an improved water source according to the UNDP (2009).

\subsection{Indirect Effects}

There are four different indirect effects. First, the indirect effects of the conversion factors mediated by education on earnings; second, the indirect effects of the conversion factors mediated by education and earnings on the decision-making index; third the indirect effects of the conversion factors mediated by education, earnings and the decision-making index on health functioning including the indirect effects of education and earnings mediated by the decision-making index on health functionings.

${ }_{28}$ As Hando $(2009,73)$ observes "when men's field fail to provide food, the women take on the responsibility of providing for the household". 
The first thing to note is the anemia indicator has no statistically significant indirect effects. Second, only education and decision-making mediate between conversion factors and BMI. Thus, education mediates between age $(-)$, urban $(+)$, and Christian $(+)$. Accordingly, older educated women achieve lower, while educated urban and Christian women achieve higher, BMI. In addition, further decision-making in the household raises BMI for women in non-polygamous relationship, for polarized relationships where women agree with beating justification but not men, and for women who absolutely reject beating justification. In addition, women who earn income achieve higher BMI by taking more decisions. Hindi $(2000,1525)$ found a similar relationship in Zimbabwe where she noted women who did not earn any cash had lower BMI achievement when they took fewer decisions in the household.

An interesting implication of these results is that the effect of decision-making varies with household environments. For instance, while in polygamous relationships higher probabilities of taking decisions alone do not raise BMI, in non-polygamous relationships they do. Decision-making has accordingly different implications in heterogeneous household environments.

\subsection{Dummies: Some Patterns}

The regions with the most negative dummies compared to Oromo are Afar (x3), Amhara (x4), Somali (x3), Gambela (x3), and Ben-Gmuz (x3). The regions with the most positive dummies are Harrari (x3), SNNP (x2), Dire Dawa (x2), and Addis Ababa (x3). The relatively few positive and numerous negative dummies entail the Oromo region outperforms most others in Ethiopia. Furthermore, the two city administrations-Dire Dawa and Addis Ababa by themselves skim about half the positive dummies. Focusing on the geographical patterns of statistical significance for the decision-making index, Tigray (North), Somali (South-East), Gambela (West), and SNNP (South) have statistically significant negative coefficients. Women in these regions accordingly have the highest probability of someone else taking decisions in the household, compared to Oromo women. In contrast, compared to Oromo women, women in Afar (North), Harari (Center-East) and Dire Dawa (Center-East) take both more shared and alone decisions. While in some northern regions (Tigray and Ben-Gmuz) women take few household decisions, all regions with positive dummies are located in either Center or Northern Ethiopia. This provides some support to the ethnographic research which found women in Northern Ethiopia have relatively higher status (Fafchamps and Quisumbing 2005; Quisumbing and Maluccio 2003). Furthermore, in two regions women have a negative dummy for both anemia and BMI, namely, BenGmuz (North) and Gambela (West). In these regions therefore women's well-being shortfall is the highest. If women's health indicators covary with those of other members in the household, then these indicators may be used as proxy indicators for overall household short term nutrition and health.

\section{Conclusion}

This paper operationalizes the capability approach by estimating which conversion factors and capability inputs correlate with women's health functioning in Ethiopia. Although the impact of low capability is multidimensional and may not reveal itself as low health functioning achievement, the findings include a positive relationship between the (preconditions) capability inputs education and (process) decision-making capability inputs 
and BMI. The anemia functioning indicator-when compared to BMI-was, however, more responsive to household wealth and to bargaining indicators such age difference between spouses, (instrumented) relative earnings and the rejection of wife beating justification by wife. Although the anemia indicator was not correlated to the decision-making index, women who shared more decisions with their husbands were better-off.

While a strict positive linear relationship between decision-making and functioning health is not supported, decision-making patterns in household clearly matter for health functioning. These results indicate that decision-making has a non-linear context dependent relationship with health functioning. As noted in Table 5, women sharing decisions with their husbands achieve better anemia scores. Cooperation in decision-making in the household may in this way help improve women's anemia health functioning. Furthermore, the computation of indirect effect reveals that the impact of decision-making on health depends on priors such as polygamy or earnings share. Thus, women in polygamous relationships can have higher probabilities of taking more decisions alone yet they are not necessarily better off compared to similar women in non-polygamous relationships. A similar finding for earnings obtains since decisions taken by women who earn more are more strongly correlated with health outcomes. Such evidence suggests in Ethiopia households are more accurately described using a non-cooperative household bargaining model because outcomes could be Pareto inefficient.

The model also points out the decision-making index cannot distinguish between women who have a BMI under 18.5 from others. The decision-making index, nevertheless, distinguishes between women with a BMI less than 20 from others. In other words, women whose BMI is less than 20 tend to take fewer decisions in the household. Some hypotheses explaining this relationship were offered. It was also observed here that women who earned more (relative to husband) could reduce the probability of BMI falling under the risk threshold of 18.5 .

To conclude, this paper highlight that policy interventions should not only focus on traditional empowerment indicators such as earnings and education. Furthermore, policy assessments and interventions should also incorporate novel indicators such as household decision-making patterns when targeting individual health functionings.

Acknowledgments This paper has benefited from the inputs of Irene van Staveren, Ellen Webbink, Jeroen Smits, Karolina Safarzynska, Jan Peil, Anita van de Kooij, Sílvia Pina Neves, the MPLUS and EQS support teams, and two anonymous referees.

Open Access This article is distributed under the terms of the Creative Commons Attribution Noncommercial License which permits any noncommercial use, distribution, and reproduction in any medium, provided the original author(s) and source are credited.

\section{References}

Abadian, S. (1996). Women's autonomy \& its impact on fertility. World Development, 24, 1793-1809.

Abate, Y. (1993). The society \& its environment. In T. Ofcansky \& L. Berry (Eds.), Ethiopia, a country study. Whitefish: Kessinger Publishing.

Agarwal, B. (1994). A field of one's own. Gender \& land rights in South Asia. Cambridge: Cambridge University Press.

Agarwal, B. (1997). "Bargaining" \& gender relations: Within \& beyond the household. Food \& Consumption Nutrition Division Discussion Paper No. 27.

Alkire, S. (2002). Valuing freedoms. Sen's capability approach \& poverty reduction. Queen Elizabeth House Series in Development Studies. 
Alkire, S. (2005). Subjective quantitative studies of human agency. Social Indicators Research, 74, 217-260.

Alkire, S., \& Deneulin, S. (2009). A normative framework for development. In S. Deneulin \& L. Sahani (Eds.), An introduction to the human development capability approach. London: EarthScan.

Alsop, R., Bertelsen, F., \& Holland, J. (2006). Empowerment in practice: From analysis to implementation. The World Bank.

Antonakis, J. (2009). Email communication on SEMNET 12/14/2009.

Bali Swain, R., \& Wallentin, F. (2008). Economic or non-economic factors-what empowers women? Uppsala Universitet Working Paper 2008:11.

Balk, D. (1994). Individual \& community aspects of women's status \& fertility in rural Bangladesh. Populations Studies, 48, 21-45.

Baltagi, B. (1998). Econometrics. New York: Springer.

Behrman, J., \& Deolalikar, A. (1989). Agricultural wages in India: The role of health, nutrition, \& seasonality. In D. Sahn (Ed.), Seasonal variability in third world agriculture: The consequences for food security. Washington, DC: IFPRI.

Bentler, P. (2006). EQS 6 structural equations programme manual.

Berhane, Y., Gossaye, Y., Emmelin, M., \& Hogberg, U. (2001). Women's health in a rural setting in societal transition in Ethiopia. Social Science and Medicine, 53, 1525-1539.

Beutelspacher, A., Martelo, E., \& García V. (2003). Does contraception benefit women? Structure, agency and well-being. Feminist Economics, 9, 213-238.

Bevan, P., \& Pankhurst, B. (1994). Ethiopian village studies. Edited \& produced jointly by the Department of Sociology, Addis Ababa University, Ethiopia \& the Centre for the Study of African Economies, Oxford.

Bhargava, A. (1997). Nutritional status \& the allocation of time in Rwandese households. Journal of Econometrics, 77, 277-295.

Biseswar, I. (2008). Problems of feminist leadership among educated women in Ethiopia. Journal of Development Societies, 24, 125158.

Bloom, S., Wypij, D., \& Gupta, D. (2001). Dimensions of women's autonomy \& the influence on maternal health care utilization in a north Indian city. Demography, 38, 67-78.

Central Statistical Agency [CAS] and ORC Macro. (2006). Ethiopia demographic and health survey 2005. Addis Ababa, Ethiopia and Calverton, Maryland, USA: Central Statistical Agency and ORC Macro.

Cheston, S., \& Kuhn, L. (2001). Empowering women through micro-finance. UNIFEM.

Chiappori, P.-A., Haddad, L., Hoddinot, J., \& Kanbur, R. (1993). Unitary versus collective models of the household. Time to shift the burden of the proof? World Bank Policy \& Research Working Paper, 1217.

Das Gupta, M. (1996). Life course perspectives on women's autonomy and health outcomes. Health Transition Review, 6, 213-231.

Dasgupta, P. (1993). An inquiry into well-being \& destitution. Oxford: Clarendon Press.

Datta, N. (2006). Joint titling-a win-win policy? Gender \& property rights in urban informal settlements in Chandigarh, India. Feminist Economics, 12, 271-298.

Dercon, S. (1999). Poverty \& deprivation in Ethiopia. World Bank.

Dercon, S., \& Krishnan, P. (2000). In sickness \& in health: Risk sharing within households in rural Ethiopia. Journal of Political Economy, 108, 688-727.

Dewan, M. (2008). Malnutrition in women. Studies on Home \& Community Science, 2, 7-10.

Di Tommaso, M. (2007). Children capabilities: A structural equation model for India. The Journal of SocioEconomics, 36, 436-450.

Diener, E., \& Diener, R. (2005). Psychological empowerment and subjective well-being. In Deepa Narayan (Ed.), Measuring empowerment: Cross-disciplinary perspectives. World Bank.

Doss, C. (1996). Women's bargaining power in household economic decisions: Evidence from Ghana. University of Minnesota, College of Agricultural, Food, \& Environmental Sciences, Staff Paper P9611.

Doss, C. (2003). Conceptualizing and measuring bargaining power within households. In K. Moe (Ed.), Women, family, and work: Writings on the economics of gender. Oxford: Wiley-Blackwell.

Easterlin, R., \& Crimmins, E. (1985). The fertility revolution: A supply-demand analysis. Chicago: University of Chicago Press.

Fafchamps, M., \& Quisumbing, A. (2005). Control \& ownership of assets within rural Ethiopian households, Working Paper.

Farah, M., Noble, K., \& Hurt, H. (2005). Poverty, privilege \& brain development: Empirical findings \& ethical implications. In J. Illes (Ed.), Neuroethics in the 21st century. Oxford: Oxford University Press.

Ferro-Luzzi, A., Branca, F., \& Pastore, G. (1994). Body mass index defines the risk of seasonal energy stress in the third world. European Journal of Clinical Nutrition, 48, 165-178. 
Ferro-Luzzi, A., Morris, S., Taffesse, S., Demissie, T., \& D’Amato, M. (2001). Seasonal undernutrition in rural Ethiopia. Washington, DC: IFPRI.

Fogel, R. (1994). Economic growth, population theory, \& physiology: The bearing of long-term processes on the making of economic policy. American Economic Review, 84, 369-395.

Foster, M., \& McLanahan, S. (1996). An illustration of the use of instrumental variables: Do neighborhood conditions affect a young person's chance of finishing high school? Psychological Methods, 1, 249-260.

Frohlich, K., Corin, E., \& Potvin, L. (2001). A theoretical proposal for the relationship between health \& disease. Sociology of Health \& Illness, 23, 776-797.

Furr, A., \& Nandita, D. (2006). The effects of social autonomy on BMI scores: A study of women in Nepal. Contributions to Nepalese Studies.

Furuta, M., \& Salway, S. (2006). Women's position within the household as a determinant of maternal healthcare use in Nepal. International Family Planning Perspectives, 32, 17-27.

Garcia, M., \& Kennedy, E. (1994). Assessing the linkages between low body mass index and morbidity in adults: Evidence from four developing countries. European Journal of Clinical Nutrition, 90-97.

Germain, A. (1975). The status \& role of women as factors in fertility behaviour: A policy analysis. Studies in Family Planning, 6, 192-200.

Ghuman, S., Lee, H., \& Smith, H. (2004). Measurement of women's autonomy according to their husbands: Results from five Asian countries. PSC Research Report, Population Studies Center, University of Michigan, Ann Arbor.

Haile, H. (2009). Targeting married women in micro-finance programmes. Ph.D. Dissertation, Wagenigen University.

Hando, F. (2009). Vulnerable widows \& drought relief in Ethiopia. Shaker Publishing.

Hindin, M. (2000). Women's power and anthropometric status in Zimbabwe. Social Science and Medicine, $51,1517-1528$.

Ibrahim, S., \& Alkire, S. (2007). Agency and empowerment: A proposal for internationally comparable indicators. Oxford Development Studies, 35, 379-403.

ICRW (International Center for Research on Women). (1997). Women's role in household decision-making: A case study in Nigeria. Washington, DC.

James, W. (1994). Introduction: The challenge of adult chronic energy deficiency. European Journal of Clinical Nutrition, 48.

Jejeebhoy, S. (1995). Women's education, autonomy, \& reproductive behaviour: Experience from developing countries. Oxford: Oxford University Press.

Kabeer, N. (1999). Resources, agency, achievements: Reflections on the measurement of women's empowerment. Development \& Change, 30, 435-464.

Kabeer, N. (2001). Conflicts over credit: Re-evaluating the empowerment potential of loans women in rural Bangladesh. World Development, 29, 63-84.

Kabira, W., Gachukia, E., \& Matiangi, F. (1997). The effect of women's role on health: The paradox. International Journal of Gynecology \& Obstetrics, 58, 23-34.

Kambhampati, U. (2009). Child schooling \& work decisions in India: The role of household \& regional gender equity. Feminist Economics, 15, 77-112.

Kaplan, D. (2000). Structural equations modeling. Beverly Hills: Sage.

Krishnakumar, J. (2007). Going beyond functionings to capabilities: An econometric model to explain \& estimate capabilities. Journal of Human Development \& Capabilities, 8, 39-63.

Krishnakumar, J., \& Ballon, P. (2008). Estimating basic capabilities: A structural equation model applied to Bolivia. World Development, 36, 992-1010.

Kuklys, W. (2005). Amartya Sen's capability approach. Theoretical insights \& empirical application. New York: Springer.

Kuklys, W., \& Robeyns, I. (2005). Sen's capability approach to welfare economics. In W. Kuklys (Ed.), Amartya Sen's capability approach. Theoretical insights \& empirical application. New York: Springer.

Laverack, G., \& Labonte, R. (2000). A planning framework for community empowerment goals \& within health promotion. Health \& Policy Planning, 15, 255-262.

Legovini, A. (2006). Measuring women's empowerment in Ethiopia: The women's development initiatives project. In R. Alsop, M. Bertelsen, \& J. Holland (Eds.), Empowerment in practice: From analysis to implementation. World Bank.

Levine, D. (1965). Wax \& gold. Chicago: University of Chicago Press.

Liere, M., Atebgo, E., Hoorweg, E., Den Hartog, A., \& Hautvat, J. (1994). The significance of socioeconomic characteristics for adult seasonal body-weight fluctuations: A study in north-western Benin. British Journal of Nutrition, 72, 472-488. 
Lim, S., Winter-Nelson, A., \& Arends-Keunning, M. (2007). Household bargaining power \& agricultural supply response: Evidence from Ethiopian coffee growers. World Development, 35, 1204-1220.

Mabsout, R., \& Van Staveren, I. (2010). Disentangling bargaining power from individual \& household level to institutions: Evidence on women's position in Ethiopia. World Development, 38, 783-796.

Malhotra, A., Schuler, S., \& Boender, C. (2002). Measuring women's empowerment as a variable in international development. Gender and Development Group. World Bank.

Mason, O. (1986). The status of women: Conceptual and methodological issues in demographic studies. Sociological Forum, 1, 284-300.

Mason, O. (1987). The impact of women's position on fertility in developing countries. Sociological Forum, 2, 718-745.

Mason, O. (2005). Measuring women's empowerment: Learning from cross-national research. In D. Narayan (Ed.), Measuring empowerment: Cross disciplinary perspectives. World Bank.

Mason, O., \& Smith, H. (2003). Women's empowerment \& social context: Results from five Asian countries. The World Bank.

Mayoux, L. (1999). Questioning virtuous spirals: Micro-finance \& women's empowerment in Africa. Journal of International Development, 11, 957-984.

Molini, V., Nubé, Ma., \& van den Boom, B. (2010) Adult BMI as a health and nutritional inequality measure: Applications at macro and micro Levels. World Development, 38, 1012-1023.

Morgan, S., \& Winship, C. (2006). Counterfactuals and causal inference: Methods and principles for social research. Cambridge: Cambridge University Press.

Mulugeta, E. (2007). Trajectory of the institute of gender studies at Addis Ababa University, Ethiopia. Feminist Africa, 9.

Muthén, B. (1989). Dichotomous factor analysis of symptom data. Social Methods \& Research, 18, 19-65.

Muthén, B. (1993). Goodness of fit with categorical and other non-normal variables. In Kenneth Bollen and Long (Eds.). Testing Structural Equations Models. Sage.

Muthén, B. (2004). MPLUS technical appendices. Los Angeles: Muthén \& Muthén.

Muthén, B., \& Muthén, L. (2008). MPLUS user's guide. Los Angeles: Muthén \& Muthén.

Narayan, D. (2005). Conceptual framework and methodological challenges. In D. Narayan (Ed.), Measuring empowerment: Cross disciplinary perspectives. The World Bank.

Osmani, L. (2007). A breakthrough in women's bargaining power: The impact of microcredit. Journal of International Development, 19, 695-718.

Panda, P., \& Agarwal, B. (2005). Martial violence, human development \& women's property status in India. World Development, 33, 823-850.

Pankhurst, H. (1992). Gender, development, \& identity. London: Zed Books.

Pelletier, D., \& Rahn, M. (1998). Trends in body mass index in developing countries. Food \& Nutrition Bulletin, 19.

Pitt, M., Khandker, S., \& Cartwright, J. (2003). Does micro-credit empower women? Evidence from Bangladesh. Working Paper.

Pitt, M., Rosenzweig, M., \& Nazmul, H. (1990). Productivity, health \& inequality in the intra-household distribution of food in low-income countries. American Economic Review, 80, 1139-1156.

Powers, M., \& Faden, R. (2006). Social justice. The moral foundations of public health \& health policy. Oxford: Oxford University Press.

Quisumbing, A. (2003). Household decisions, gender, and development. A synthesis of recent research. Washington, DC: IFPRI.

Quisumbing, A., \& Maluccio, J. (2000) Intrahousehold allocation \& gender relations: New empirical evidence from four developing countries. FCND Discussion Paper, 84.

Quisumbing, A., \& Maluccio, J. (2003). Resources at marriage \& intrahousehold allocation: Evidence from Bangladesh, Ethiopia, Indonesia, \& South Africa. Oxford Bulletin of Economics \& Statistics.

Rispin, P. (1998). Combating iron deficiency in Ethiopia: Exploring the link between iron supplementation \& malaria. The International Research Development Center.

Robeyns, I. (2004). Justice as fairness \& the capability approach. Working Paper.

Robeyns, I. (2005). The capability approach: A theoretical survey. Journal of Human Development and Capabilities, 6, 93-114.

Rubinstein, A. (1991). Comments on the interpretation of game theory. Econometrica, 59, 904-921.

Ruger, J. (2010). Health \& social justice. Oxford: Oxford University Press.

Sahn, D., \& Alderman, H. (1988). The effects of human capital on wages, \& the determinants of labor supply in a developing country. Journal of Development Economics, 29, 157-183.

Sahn, D., \& Younger, S. (2009). Measuring intra-household health inequality: Explorations using the body mass index. Health Economics, 18, 13-19. 
Samman, E., \& Santos, M. (2009) Agency and empowerment: A review of concepts, indicators, and empirical evidence. Prepared for the 2009 Human Development report in Latin America and the Caribbean.

Santow, G. (1995). Social roles and physical health: The case of female disadvantage in poor countries. Social Science \& Medicine, 40, 147-161.

Scrimshaw, N. (1996). Nutrition \& heath from womb to tomb. Nutrition Today.

Sen, A. (1985). Commodities \& capabilities. Amsterdam: Elsevier.

Sen, A. (1990). Gender \& cooperative conflict. In Irene. Tinker (Ed.), Persistent inequalities. Women \& world development. Oxford: Oxford University Press.

Sen, A. (1993). Capability \& well-being. In M. Nussbaum \& A. Sen (Eds.), The quality of life. Oxford: Clarendon Press.

Sen, A. (1999). Development as freedom. Garden City: Anchor Books.

Sen, A. (2001) Reply. Economics and Philosophy, 17, 51-66.

Sen, A. (2002) Rationality \& Freedom. Harvard Belknap.

Shetty, P., Soares, M., \& James, W. (1994). Body mass index: Its relationship to basal metabolic rates \& energy requirements. European Journal of Clinical Nutrition, 48, 28-37.

Strauss, J., \& Thomas, D. (1998). Health, nutrition, \& economic development. Journal of Economic Literature, 36, 766-817.

Thomas, D. (1990). Intra-household resource allocation: An inferential approach. Journal of Human Resources, 25, 635-664.

UNDP (United Nations Development Programme). (1995). Human development report. Oxford: Oxford University Press.

UNDP (United Nations Development Programme). (2008/9) Human Development Report. Oxford: Oxford University Press.

University of Maryland Medical Center. (2008). Accessed August 30, 2008.

USDA. (2006). Crop calendar of Ethiopia.

Webb, P., \& von Braun, J. (1994). Famine \& food security in Ethiopia: Lessons for Africa. London: Wiley.

WFP (World Food Program). (2005). Food needs \& new safety programme in Ethiopia.

WHO (World Health Organization). (1999). An assessment of reproductive health needs in Ethiopia, Geneva.

Williams, J. (2005). Measuring gender \& women's empowerment using confirmatory factor analysis. Institute of Behavioral Science, Working Paper.

Wolffe, J., \& De-Shalit, A. (2007). Disadvantage. Oxford: Oxford University Press. 